Research Article

\title{
Low-Frequency Carbody Sway Modelling Based on Low Wheel-Rail Contact Conicity Analysis
}

\author{
Yi Wu $\left(\mathbb{D}\right.$, Jing Zeng, Sheng Qu, Huailong Shi $\mathbb{D}^{D}$, Qunsheng Wang $\mathbb{D}$, and Lai Wei \\ State Key Laboratory of Traction Power, Southwest Jiaotong University, Chengdu, Sichuan, China \\ Correspondence should be addressed to Lai Wei; 707101305@qq.com
}

Received 8 October 2020; Revised 7 December 2020; Accepted 9 December 2020; Published 21 December 2020

Academic Editor: Nicolo Zampieri

Copyright $\odot 2020 \mathrm{Yi} \mathrm{Wu}$ et al. This is an open access article distributed under the Creative Commons Attribution License, which permits unrestricted use, distribution, and reproduction in any medium, provided the original work is properly cited.

\begin{abstract}
Low-frequency carbody swaying on China's high-speed trains is not only an impediment to ride comfort but it may also be an operational risk under some extreme situations. To study the mechanism and mitigate the carbody swaying problem for highspeed trains, a multibody dynamics model was established based on both linear and nonlinear analyses. Whilst it is generally assumed that carbody swaying is predominantly caused by carbody hunting motion, the results in this paper has shown that, under certain boundary conditions, bogie-hunting motion can also lead to low-frequency carbody swaying. This low-frequency swaying phenomenon was also found to be caused by the excessively low wheel-rail contact or mismatched suspension parameters. Parametric optimization analysis was accordingly conducted from the perspective of the wheel-rail contact relationship and the suspension system. The analysis indicated that although optimizing the suspension parameters can meet the requirement of vehicle stability, bogie's vibration worsen when the wheel profiles wear over time. Overall, while rail reprofiling was found to be one of the fundamental solutions to mitigate carbody swaying, it is cost prohibitive for most routine operational applications. Thus, for economic considerations and the fact that low wheel-rail contact conicity is also a contributing factor to carbody swaying, vehicles with worn wheels can also be operated on the rail line, which was successfully verified by the field data presented in this paper.
\end{abstract}

\section{Introduction}

With the rapid development and widespread application of China's high-speed railway systems, the phenomenon of low-frequency carbody swaying, which is a function of vehicle hunting motion, has become an increasing occurrence during high-speed vehicle operations. The hunting motion of the vehicle system is essentially an issue of vehicle system stability that can be divided into carbody and bogie-hunting motions [1]. When carbody hunting stability occurs, the vibration of the carbody can detrimentally deteriorate and cause a decay in ride comfort. In some extreme cases, carbody vibrations may also cause an undesired risk to operational safety $[2,3]$. The bogiehunting motion, on the other hand, is dominated by the periodic hunting motion of the bogie. When this bogiehunting stability occurs, there is often a sharp deterioration in the safety indicators such as the derailment coefficient and wheel axle lateral force. This is detrimental to the operation/driving of the vehicle and is undesired.

With the development of railway sciences, a lot of research studies have been devoted to bogie-hunting stability of railway vehicle systems. This is partly because bogiehunting stability directly causes the rapid deterioration of the safety operating indicators with the corresponding endangerment of railway vehicle operations [4-15]. By contrast, the literature reviewed is limited on research studies related to carbody hunting movement. In 1957, Matsudaira [16] discovered that the carbody sways significantly within a certain speed range. According to the vehicle hunting movement study based on rolling rig testing, when the speed increases, the bogie shakes violently while the carbody remains relatively stable. With respect to the carbody hunting characteristics of a train, Fujimoto and Miyamoto [17] believed the vibration of the trailing car is often significantly greater than that of other cars because of the yawing mode 
and the aerodynamics influence in the tunnel. Based on field data and numerical simulation analyses, Fujimoto et al. [18] also concluded that gauge enlargement is the probable cause of the carbody abnormal vibration on the Jyoetsu Shinkansen line. Sun et al. [19] explained and demonstrated this phenomenon using high-speed inspection vehicle modeling. From the modeling results, it was observed that the damping factor of the vehicle's upper center roll mode first increased and then decreased with an increase in the vehicle speed. Additionally, it was also observed that the wheel-rail relationship mismatch makes the overall hunting modedamping factor to be very small, a typical phenomenon associated with car hunting.

Huang et al. [20] also used the root locus method to analyze the carbody hunting phenomenon and revealed that adjusting the yaw damper's parameters can eliminate the hunting phenomenon. Shi and $\mathrm{Wu}$ [21] and Wei et al. [22] analyzed the carbody shaking phenomenon by establishing a rigid-flexible coupling dynamic model. In the modeling analysis, the local high-frequency vibration was assumed to be due to the resonance of the hunting frequency and the coupling of elastic modes. Shi et al. conducted a large number of line driving tests and analyzed the typical vibration characteristics of a carbody [23]. Luo et al. also successfully conducted a simulation study on high-speed trains' dynamic characteristics, including carbody hunting movement based on the nonlinear rubber spring model [24]. In addition, Sun and Lei et al. also studied carbody hunting of an electric locomotive [3, 25]. Using the root locus method, Chi et al. [26] have reported that the grinding deviation of the rail profile can greatly affect the vehicle operation quality and that it is easy to induce the vehicle's carbody and/or bogie-hunting motion.

In general, improving the wheel-rail contact relationship and adjusting the suspension system parameters are considered as some of the key remedial measures to eliminate or reduce carbody swaying. Zeng et al. [27] proposed a wheel profile correction scheme to consider both bogie frame and carbody vibrations. Li et al. reduced the risk of low-frequency vehicle hunting caused by the lower equivalent taper by increasing the wheel profile end slope [28]. Sun et al. performed simulations and then concluded that increasing the wheelset's inner distance can eliminate the swaying phenomenon [19]. Using a line test for verification, Hou et al. [29] mitigated bogie and carbody hunting motions by optimizing the wheelset guidance stiffness and wheelset wheel profile modification.

Xia et al. used an active low-frequency inerter-springdamper type dynamic vibration absorber to mitigate the carbody swaying phenomenon [2]. In Xia's study, it was shown that the standard evaluation indicators do not always directly characterize the carbody swaying problem. Other indicators such as carbody vibration or ride index need to be considered for indirect performance evaluation. The typical low-frequency vibration characteristics of carbody swaying can be easily measured using active control or nonlinear components. This is why the evaluation index for carbody swaying is one of the research hotspots in recent years. From the peak value of the timefrequency signal of carbody acceleration, Wu et al. and Sun et al. proposed a corresponding evaluation method for swaying and ride comfort standardization during carbody swaying [30, 31]. Xia et al. used empirical mode decomposition (EMD) and Hilbert transform to quantify the carbody swaying signal [2]. Chen and Shen, on the other hand, used fuzzy mathematics to model and quantify the phenomenon of carbody swaying [32].

Current research believes that many reasons can lead to the carbody swaying, such as the mismatch of suspension parameters, poor wheel-rail matching, and low wheel-rail friction coefficient. [1]. At times, the swaying can disappear quickly while in some cases, it can exist for a long time. It is generally believed that carbody hunting is the main cause of carbody swaying. Carbody hunting or instability behavior is caused by the resonance of the bogie-hunting frequency and carbody suspension mode frequency. This results in a decrease in the vehicle system's damping ratio, leading to significant carbody swaying. In the past, it has often been believed that this hunting movement generally occurred only at low speeds and that the impact of vibration could be eliminated by increasing the speed beyond the resonance zone. However, with the rapid development and widespread application of China's highspeed railway systems, both the operating environment and boundary conditions have become increasingly complex. Carbody swaying also occurs during the highspeed railway operations.

This paper focuses on vehicle-swaying phenomenon observed on China's high-speed railway trunk lines as an example and analyzes it from the perspective of both linear and nonlinear systems. In the study, the reason for carbody swaying is considered to be related to the vibration transmitted from the bogie-hunting motion due to low wheel-rail contact conicity and mismatching of the suspension parameters. This paper conducts an optimization analysis from the perspective of the wheel-rail matching relationship and the suspension system to reduce carbody swaying motion. The optimized methods, including improving the wheel-rail contact relationship, adjusting the stiffness of the rotary arm attachment point (primary suspension connection), the stiffness of the air spring, and the stiffness of yaw damper, were analyzed and are presented in this paper. The study also included vehicle simulation analysis with new and worn wheel profiles under the adjusted suspension parameters. The study results showed that although the adjustment of the suspension parameters can improve the vehicle-swaying phenomenon with the new wheel profiles, the bogie's vibration would still be affected by the worn wheel profiles. Comprehensive modeling analysis suggests that the reprofiling of the rail can fundamentally solve the swaying phenomenon without any negative impacts. For example, considering economic conditions and other factors, the train can operate on the concerned line with worn wheel profiles. Field data supported this and substantiated that this method can effectively reduce the carbody swaying phenomenon. 


\section{Field Test Data Analysis}

This section of the paper describes a field test on a highspeed train with the carbody swaying. The vehicle's operating speed was $300 \mathrm{~km} / \mathrm{h}$, and the operating route is mainline from Changsha to Guangzhou in China. Data collected and analyzed included acceleration, speed, wheel profile, and rail profile.

2.1. Acceleration Analysis. The layout of vehicle acceleration sensors is shown in Figure 1(a). The three-way acceleration sensor that detects carbody vibration is installed on the carbody floor directly above the center of the front and rear bogies, $1 \mathrm{~m}$ away from the carbody central axis, as shown in Figure 1(b). The acceleration sensor that detects the bogie frame vibration is installed separately at the front and rear frame ends, above the axle box, as shown in Figure 1(c). The data were acquired at a frequency of $2000 \mathrm{~Hz}$. A SoMat eDAQ data logger, supplied by HBM company, was used for collecting the data. The carbody and bogie frame acceleration sensors were sourced from Lance and BK companies, respectively. The measurement range was $2 \mathrm{~g}$ and $70 \mathrm{~g}$, with a sensitivity coefficient of 1000 and 1 , respectively.

Since the carbody swaying frequency is generally low, the acceleration signal at the front and rear ends of the carbody was filtered using a $0.5-10 \mathrm{~Hz}$ frequency module. This frequency was then subjected to a short-time Fourier transform to obtain the time-frequency characteristic diagram shown in Figures 2(a) and 2(b). The main frequency of vibration at the front and rear ends of the carbody was around $1.5 \mathrm{~Hz}$.

To quantify the vibration characteristics of the vehicle body, the lateral acceleration was constituted as the timefrequency signal located at the front and rear ends of the carbody with a $0.5-3 \mathrm{~Hz}$ fourth-order Butterworth filter shown in Figure 2(c). The figure shows that the acceleration of carbody rear-end vibration is larger compared to the front end, with a peak acceleration value of $1.21 \mathrm{~m} / \mathrm{s}^{2}$, while the peak acceleration of the carbody front end is about $0.86 \mathrm{~m} / \mathrm{s}^{2}$. Figure 2(d) compares the lateral acceleration of the carbody with the bogie frame filtered in the range of $0.5-3 \mathrm{~Hz}$. Clearly, the figure shows a phase difference between the two components and that the bogie frame's lateral acceleration is slightly larger than the carbody lateral acceleration. This indicates that the bogie also has a concurrent hunting motion phenomenon.

From the frequency domain, the main frequency of the carbody and bogie vibration is basically the same. To analyze the carbody vibration posture with carbody swaying, some of the data were extracted for further analysis, which is shown in Figure 2(e). The data show that the carbody front and rear end lateral vibrations are relatively synchronized and that the phase difference between the two (front and rear) is small or almost zero. This indicates that there is a prominent characteristic of the carbody lateral movement or rolling motion. The vertical vibration of the carbody at the left and right ends have a $\pi$ phase, exhibiting an obvious carbody rolling motion posture characteristics.
2.2. Wheel-Rail Contact Conditions. The wheelset profiles of the tested vehicle were measured to study the wheel-rail contact conditions. As shown in Figure 3(a), the wear depth between each wheel profile and the LMB10 standard profile do not exceed $0.2 \mathrm{~mm}$, which suggests an ideal lathing condition. The track profiles at different kilometers ranging from $\mathrm{k} 1870+430$ upline to $\mathrm{k} 1902+000$ downline were measured. Figure $3(\mathrm{~b})$ shows the track profile measured at the upstream of k1870 +600 and the standard CHN60 track profile. By comparison, it is clear that the rail surface is overpolished, which is caused by the insufficient polishing control accuracy of rail reprofiling process and that the rail shoulder is significantly lower than the standard rail surface profile. The equivalent conicity between the rail surface and the corresponding wheelset at different kilometers was calculated based on the UIC519 standard [33]. The corresponding results are shown in Figure 3(c), which indicate that the equivalent conicities of both the LMB10 and the measured wheel profiles are much smaller than one of the LMB10 standard wheel profiles and the CHN60 matching.

2.3. Ride Comfort Index Analysis. The vehicle ride index is an essential indicator for evaluating the vehicle body vibration and passenger comfort. This evaluation is primarily based on the measurement of carbody vibration acceleration. According to GB/T 5599-2019 [34], the standard measurement time is $5 \mathrm{~s}$. The measurement points on the carbody's interior floor deviated from the central line by $1000 \mathrm{~mm}$, above the 1st and 2nd bogies, respectively. Equation (1) illustrates the model for computing the index:

$$
W=3.57 \sqrt[10]{\frac{A^{3}}{f} F(f)},
$$

where $A$ is the vibration acceleration $\left(\mathrm{m} / \mathrm{s}^{2}\right), f$ is the vibration frequency $(\mathrm{Hz})$, and $F(f)$ is the frequency correction coefficient, respectively. For passenger vehicles, the limiting values for ride comfort are 2.5, 2.75, and 3.0 for excellent, medium, and qualified levels, respectively.

Figure 4(a) shows that the lateral ride index of the carbody front end is better and that it is less than 2.5 for most of the time span (window) evaluated. However, a small part of the time window shows an index larger than 2.5 but less than 2.75. By contrast, the index of the carbody rear end is significantly worse than the one on the carbody's front end. When the vehicle operates at an operating speed of $300 \mathrm{~km} /$ $\mathrm{h}$, most of the indicators exceed 2.5 and are still within the 3.0 threshold. The vehicle lateral ride index in some sections exceeded 3.0 for a longer period of time, which dramatically reduces the comfort of passengers. Figure 4(b) indicates that as the speed increases, there are two peaks in the vehicle lateral ride index. The first peak occurs at about $225 \mathrm{~km} / \mathrm{h}$ whilst the second peak is occurring at about $300 \mathrm{~km} / \mathrm{h}$.

\section{MBS High-Speed Vehicle Modelling}

A multibody system (MBS) railway vehicle model is established based on a high-speed passenger train with an operating speed of $300 \mathrm{~km} / \mathrm{h}$. This SIMPACK vehicle model 


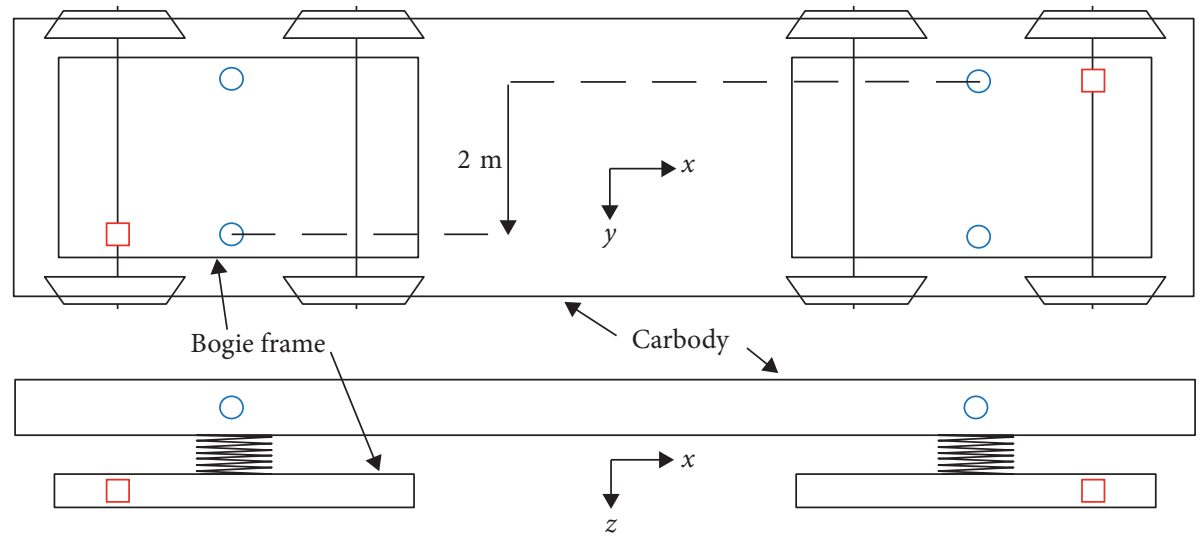

(a)

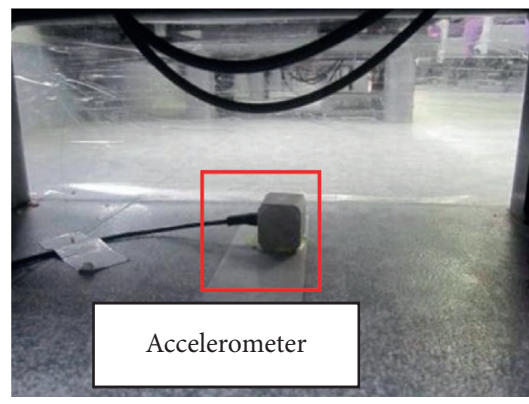

(b)

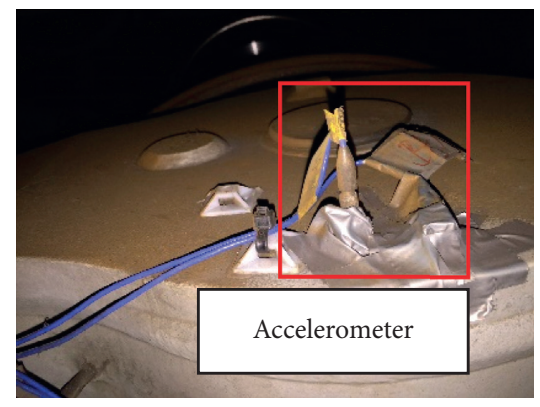

(c)

Figure 1: (a) Sensor location (red boxes and blue circle represent the accelerometers on the bogie frame and carbody floor, respectively); and the field test photos. (b) Accelerometer on the carbody floor. (c) Bogie frame.

with 50 degrees of freedom (DoFs), as shown in Figure 5, includes one carbody, two bogie frames, eight axle boxes, four wheelsets, and related detailed suspension components. The carbody and bogie frame were assigned with six independent DoFs, each of which allows free movements or rotations in the longitudinal, lateral, and vertical directions, respectively. The wheelset amounts to six DoFs, while the movement and rotation in the vertical direction are independent. The axle box can only rotate around the axle.

To simulate the swaying phenomenon in operation, the damping of the primary vertical damper, the secondary lateral damper, the secondary vertical damper, the yaw damper, and the lateral stopper were all modelled as nonlinear force units, and the track irregularity, as measured by the Wuhan-Guangzhou mainline, is shown in Figure 6. The wheel profile and rail profile were consistent with the LMB10 standard wheel profiles and the actual measured rail, respectively.

To verify the accuracy and reliability of the model formulation, the natural frequencies of the rigid carbody modes were tested and thereafter, the simulations were compared. The main frequency of the carbody of the simulation model was found to be consistent with the main frequency obtained during field experimentation.

Simulation analyses were thereafter performed using dynamic models, and the results were compared with the measured data in both the time and frequency domains. The corresponding results are shown in Figure 7.
Figure 7(a) indicates that the amplitude of the simulation and the field data in the time domain are relatively consistent. After the frequency band of $0.5-3 \mathrm{~Hz}$ past filtering, the peak value of the carbody front-end lateral acceleration obtained from simulation is $0.641 \mathrm{~m} / \mathrm{s}^{2}$ whilst it is $0.698 \mathrm{~m} / \mathrm{s}^{2}$ for the field data. The carbody rear-end lateral acceleration's peak value is $0.987 \mathrm{~m} / \mathrm{s}^{2}$ and $1.079 \mathrm{~m} /$ $\mathrm{s}^{2}$ for the field data, which indicates good reproducibility of the vibration characteristics. The frequency-domain characteristics of the acceleration signal were modelled and quantified using Fourier analysis in Figure 7(b). From the results, it was observed that the main vibration frequencies are the same with peak values of $1.499 \mathrm{~Hz}$ and $1.466 \mathrm{~Hz}$, respectively.

By comparing the field test and numerical simulation results, the MBS vehicle dynamic model was successfully substantiated and validated. Thus, it was concluded that the MBS model was suitable for modeling the carbody swaying mechanism.

\section{Numerical Simulation Analysis}

4.1. Linear Stability Analysis. Analysis by simplifying a complex nonlinear system to an approximate linear system is one of the common processing methods used in many engineering applications. The root locus method is one such popular mathematical analysis methods used to analyze the stability of the linear system. 


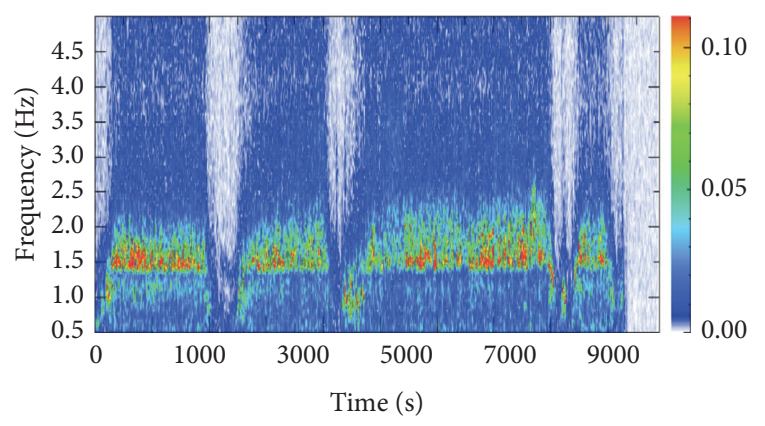

(a)

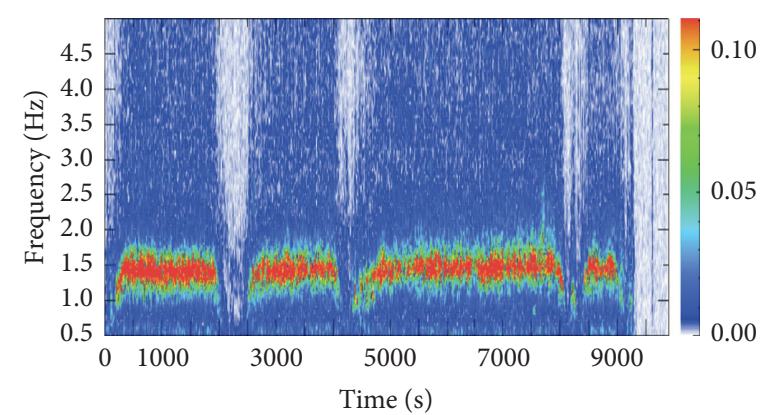

(b)

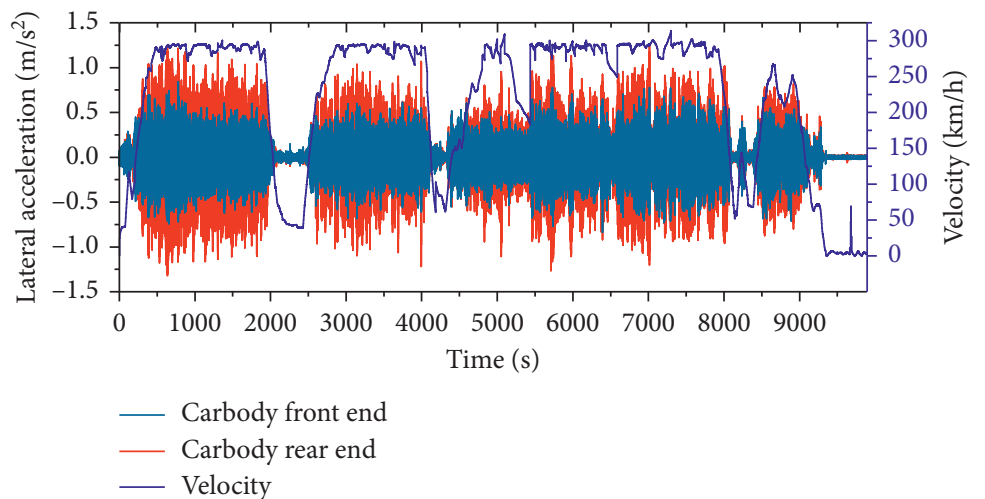

(c)
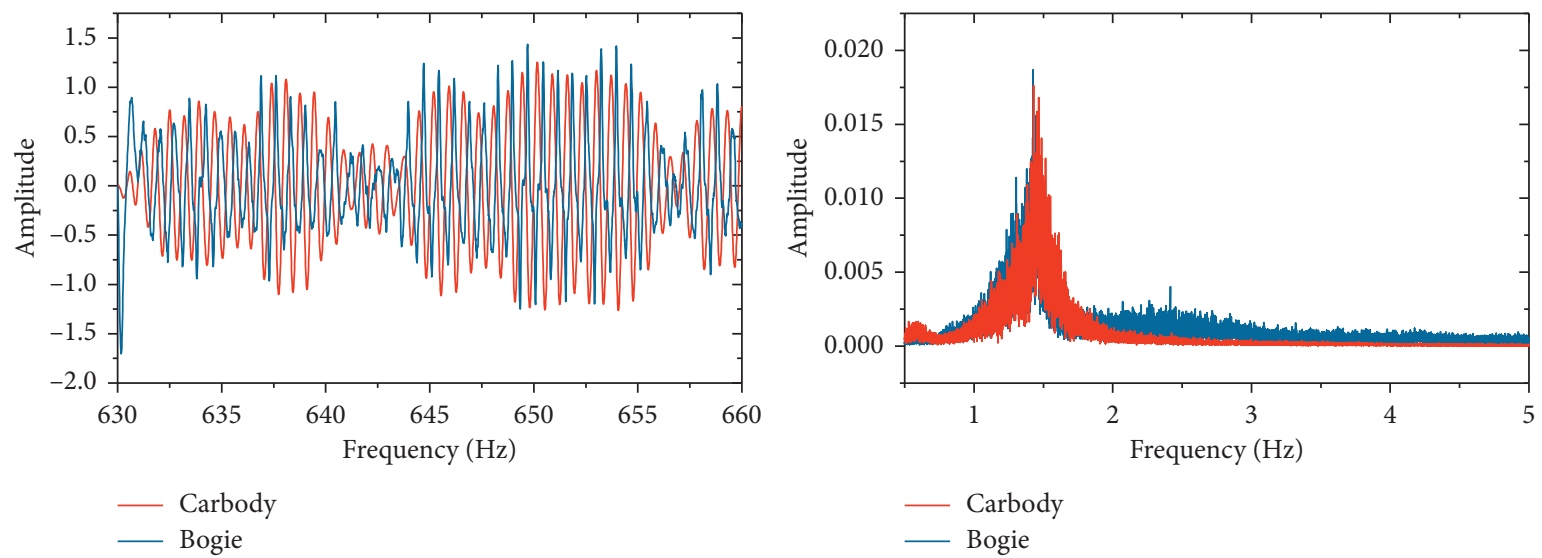

(d)
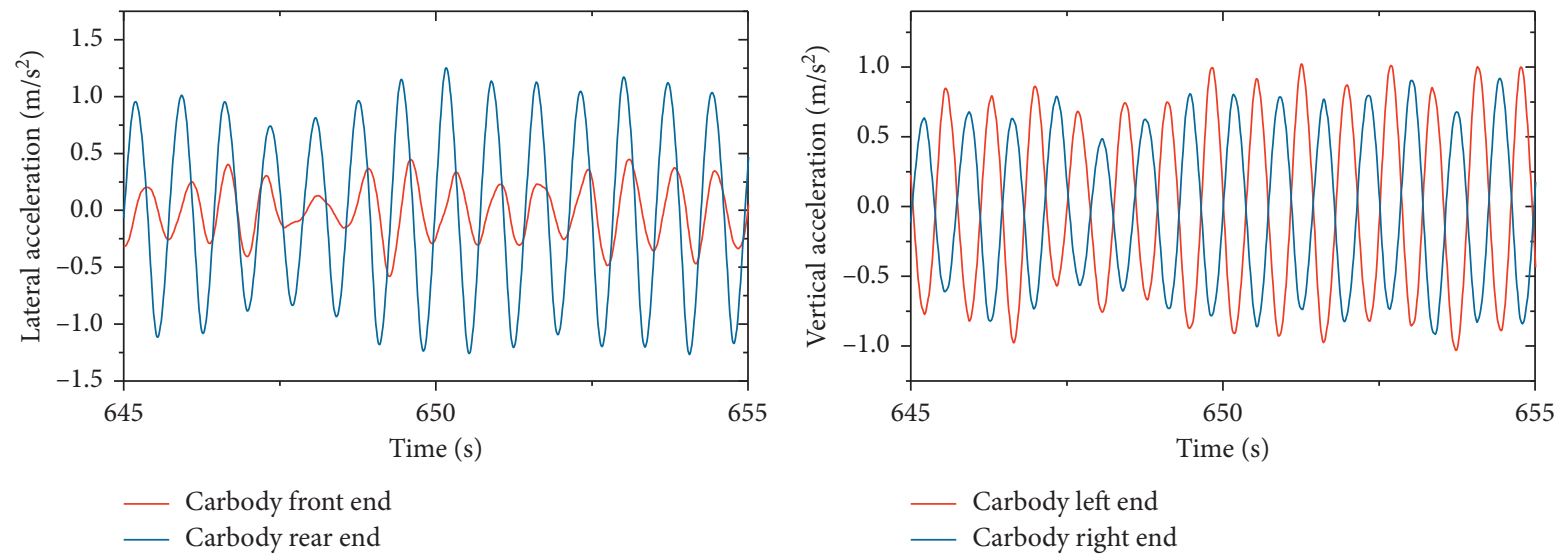

(e)

FIGURE 2: Line tested lateral acceleration on (a) carbody front-end time-frequency domain, (b) carbody rear-end time-frequency domain, (c) time domain $(0.5-3 \mathrm{~Hz}),(\mathrm{d})$ carbody and bogie in time and frequency domain, and (e) carbody vibration modes. 


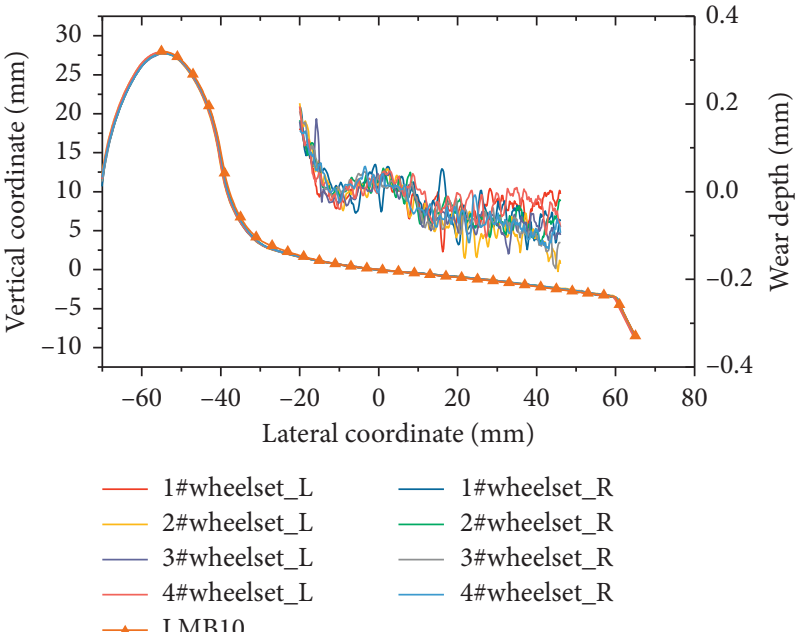

(a)

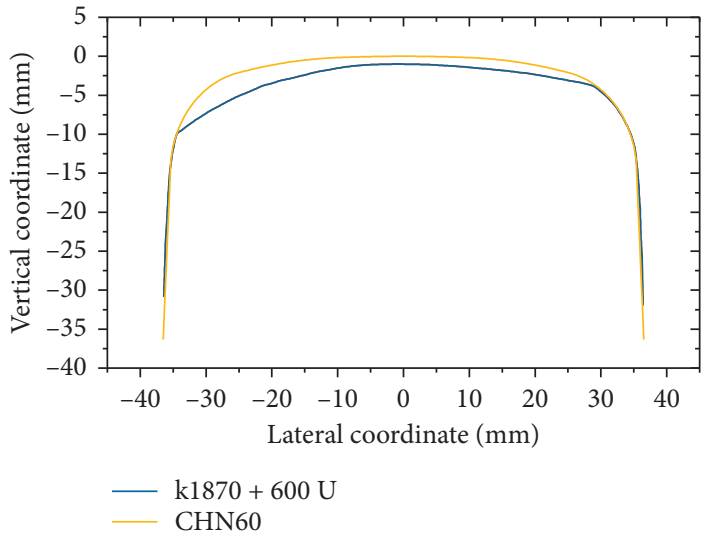

(b)

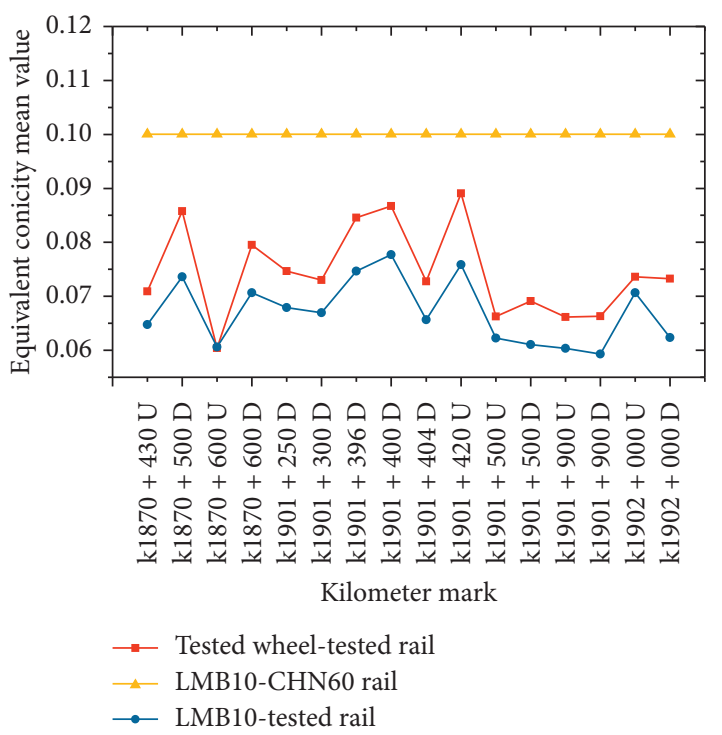

(c)

FIGURE 3: The profile of (a) wheelsets, (b) rail, and (c) the equivalent conicity mean value (U means the upline, which represents train's running direction towards Beijing, and D means the downline, which represents train's running direction away from Beijing).

The following matrix form can represent a linear dynamic system containing " $n$ " DoFs:

$$
\dot{x}=A x,
$$

where $n$-dimensional coefficient matrix $A$ is the Jacobian matrix of the linear system at $x=0$ relative to the variable $x$. The solution of equation (2) is as follows:

$$
x=B e^{\eta t} .
$$

Substituting equation (3) into equation (2) gives the following:

$$
(A-\eta E) B=0 .
$$

For $B$ to have a nonzero solution, it is necessary to make the coefficient determinant $|A-\eta E|=0$ and, thus, yielding a solution of $\eta=a+b i$. For a system with undamped natural frequency, $f_{0}=\sqrt{a^{2}+b^{2}}$. However, for a damped natural frequency $f=b$, and the damping ratio is $\zeta=-a / \sqrt{a^{2}+b^{2}}$.

The nonlinear element is linearized in the established vehicle model using the following steps: taking the equivalent conicity value for the wheel-rail contact conicity, then taking the values near the origin for other nonlinear force elements, and performing root locus analysis on the linearized vehicle system. Considering a vehicle speed ranging from $10 \mathrm{~km} / \mathrm{h}$ to $500 \mathrm{~km} / \mathrm{h}$ at an incremental speed interval of $2 \mathrm{~km} / \mathrm{h}$, the frequency and damping ratio results presented in Figure 8 were obtained.

It can be seen in Figure 8 that there are two hunting motion modes. $1 \#$ and $2 \#$ hunting movements are the hunting movement of the rear (trailing) and front (leading) bogie, respectively. As the vehicle speed increases, the frequency of the hunting motion increases significantly. When it passes through the carbody's natural mode frequencies, 


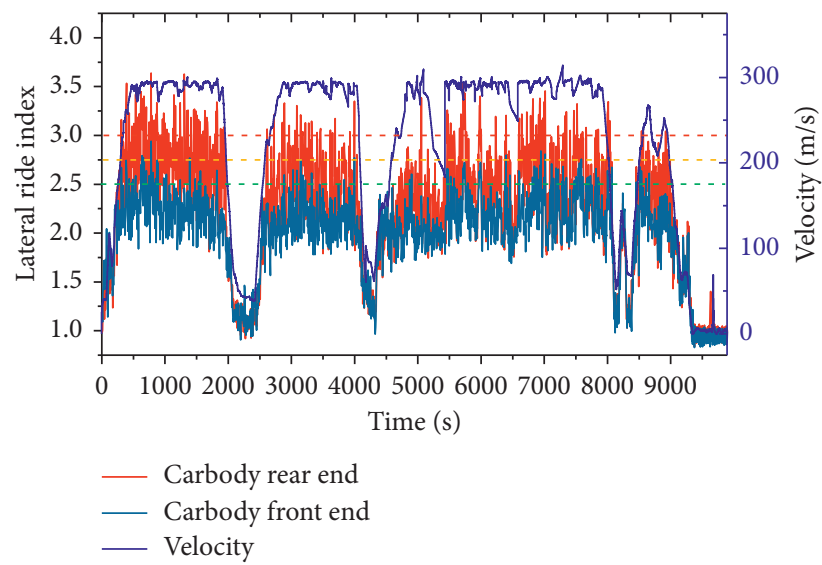

(a)

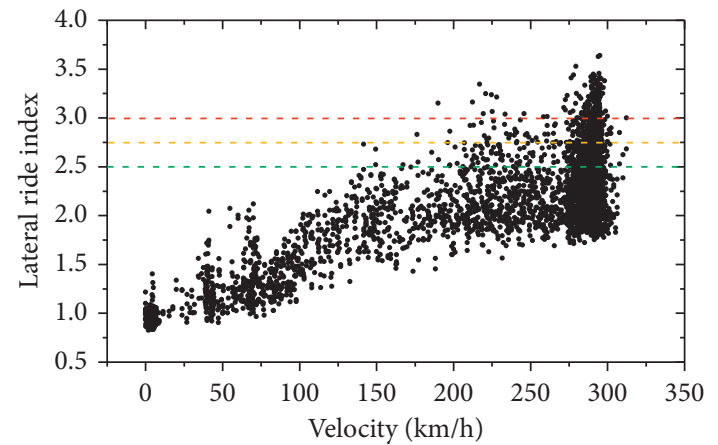

(b)

FIgURE 4: Lateral ride index in the field test based on the (a) time and (b) velocity domain.

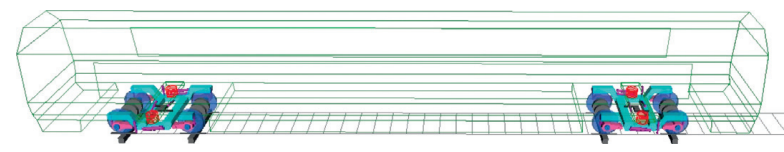

Figure 5: High-speed train simulation model.

the yaw, upper, and lower swaying mode frequencies change marginally. The original value can be restored when the hunting motion frequency has diverted significantly. Figure 8(b) shows that the carbody bounce and pitch modes' damping ratio are unchanged, showing a straight line with a slight change in the carbody's yaw damping ratio. When the hunting motion mode frequency crosses the frequency carbody yaw mode (at around $100 \mathrm{~km} / \mathrm{h}$ ), the carbody yaw mode-damping ratio decreases slightly and then, gradually increases.

In comparison to the yaw mode, the changes in the damping ratio of the upper and lower swaying mode are significantly more evident in Figure 8. When the hunting movement frequency crosses the lower swaying frequency (at about $62 \mathrm{~km} / \mathrm{h}$ ) of the carbody, the lower swaying drops significantly, i.e., from 0.167 to 0.096 , and then quickly recovers to a slightly lower value than the original damping ratio as the vehicle speed increases. When the second hunting movement crosses the carbody's upper swaying frequency at $162 \mathrm{~km} / \mathrm{h}$, the upper swaying mode-damping ratio significantly decreases, dropping from 0.164 to 0.053 . With an increase in the speed to $236 \mathrm{~km} / \mathrm{h}$, the first hunting movement's frequency crosses the carbody upper swaying frequency, and the upper swaying mode-damping ratio has an obvious rebound and returns slightly below the original frequency. The second hunting movement damping ratio increases significantly when the hunting movement frequency intersects the carbody's lower and upper swaying mode frequencies, and, then, gradually decreases as the speed increases. The first hunting movement indicates a small initial increment before the frequency rendezvous and then decreases as the speed increases.
4.2. Nonlinear Stability Analysis. To describe the carbody's vibration motion, the main frequency and energy concentration rate need to be defined. The main frequency of the carbody vibration can be defined as the frequency corresponding to the power spectral density (PSD) peak value in the frequency domain. The energy concentration rate is then used to describe the vibrational energy ratio at a certain frequency, which can be expressed as follows:

$$
\varepsilon=\frac{\int_{f_{0}-\Delta f}^{f_{0}+\Delta f} f * P(f) d f}{\int_{0}^{+\infty} f * P(f) d f},
$$

where $f_{0}$ is the specific frequency, $\Delta f$ is the frequency range, and $P$ is the PSD function. In this paper, the $f_{0}$ and $\Delta f$ are the main frequency and $0.5 \mathrm{~Hz}$, respectively.

The vehicle model was utilized for numerical simulation analysis. The vehicle speed condition was consistent with a linear system. The simulation time was $30 \mathrm{~s}$, with similar input parameters as previously discussed in Section 3. The carbody and bogie frame acceleration bands were filtered using the $0.5-10 \mathrm{~Hz}$ and $0.5-40 \mathrm{~Hz}$ frequencies, respectively. Figure 9 shows the comparison between the carbody vibration's main frequency based on nonlinear analysis. The carbody and hunting frequencies were obtained using the root locus analysis. The main frequency, energy concentration rate, and the lateral ride index of the carbody and bogie frame were determined as shown in Figure 10.

Figure 10 shows that the vibration's main frequency of the carbody and the bogie frame is in a relatively random fluctuating state when the speed is less than $60 \mathrm{kn} / \mathrm{h}$. At the same time, Figure 10 shows that the energy concentration rate is very low. As the speed increases, the carbody vibration's main frequency coincides with the hunting frequency from the root locus analysis. Figure 10 shows that as energy concentration rate of the carbody vibration begins to increase, the ride index increases to a certain extent. When the vehicle speed increases to $150 \mathrm{~km} / \mathrm{h}$, it is seen that the bogie vibration's main frequency also decreased rapidly from the original high-frequency random fluctuations, 


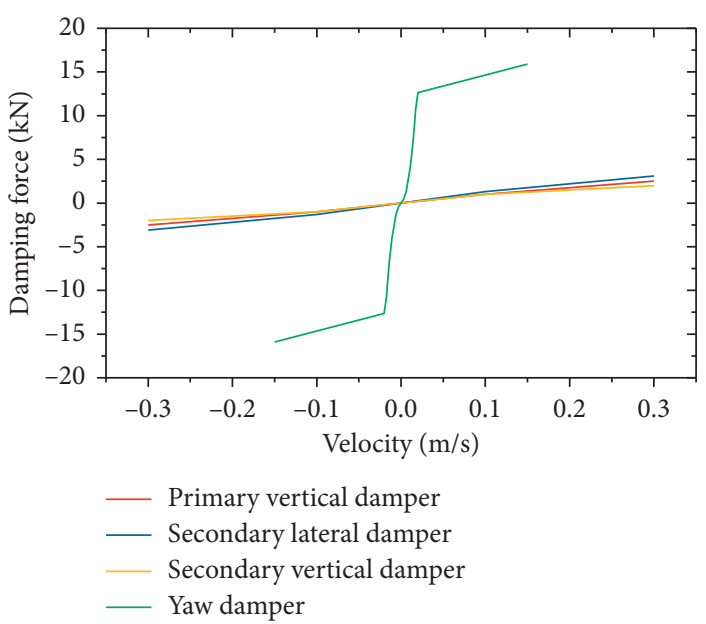

(a)

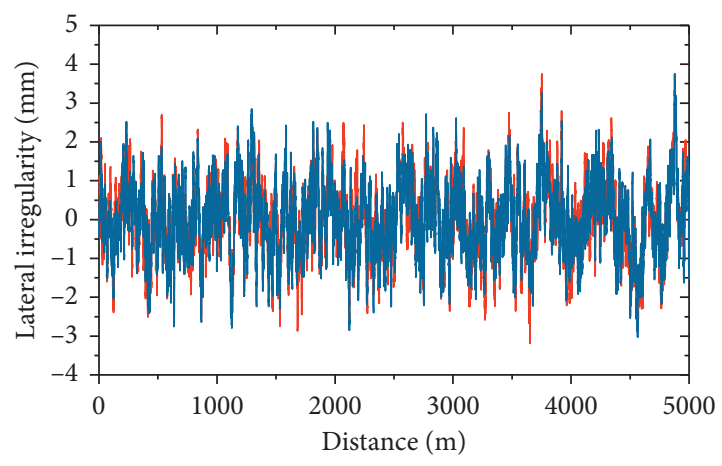

- Left rail

- Right rail

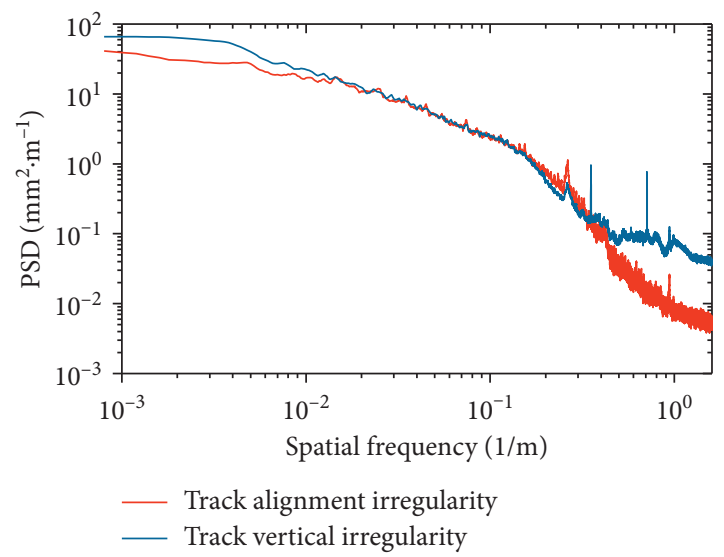

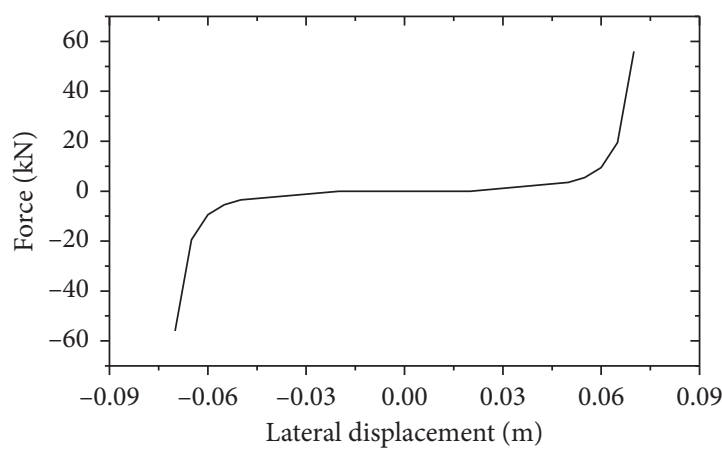

(b)

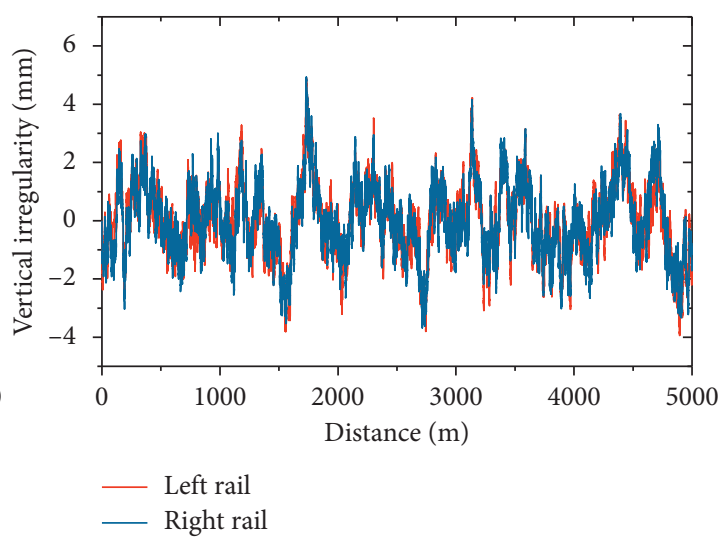

(c)

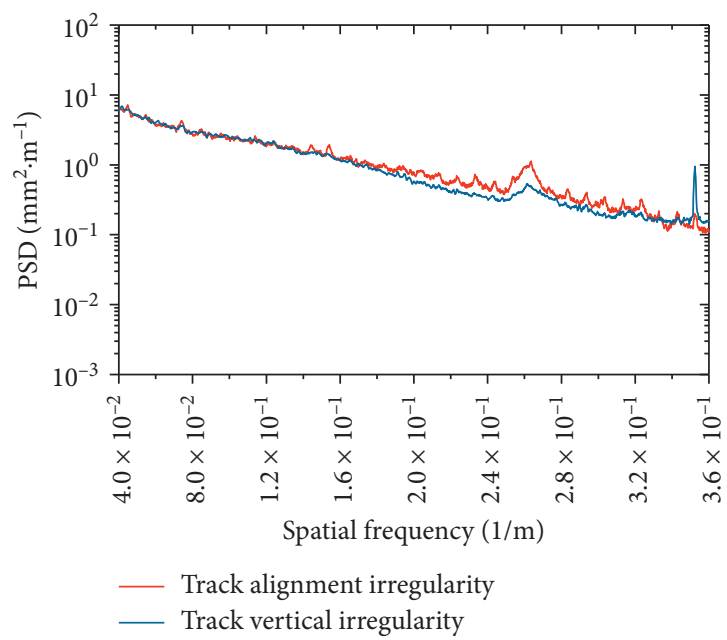

(d)

Figure 6: Nonlinear parameters of the simulation model. (a) Damping forces of primary vertical damper, secondary lateral damper, secondary vertical damper, and yaw damper. (b) Stop force of the secondary lateral stopper. (c) Track irregularity. (d) The PSD of track irregularity.

which is same as the main frequency of the carbody vibration.

When the vehicle speed increases to $170 \mathrm{~km} / \mathrm{h}$, the second hunting frequency (obtained using the root locus analysis) crosses the frequency of the carbody's upper swaying point. At this time, it is seen in Figure 10 that the volatility of the main frequency of the carbody vibration is further reduced, and the energy concentration rate reaches 


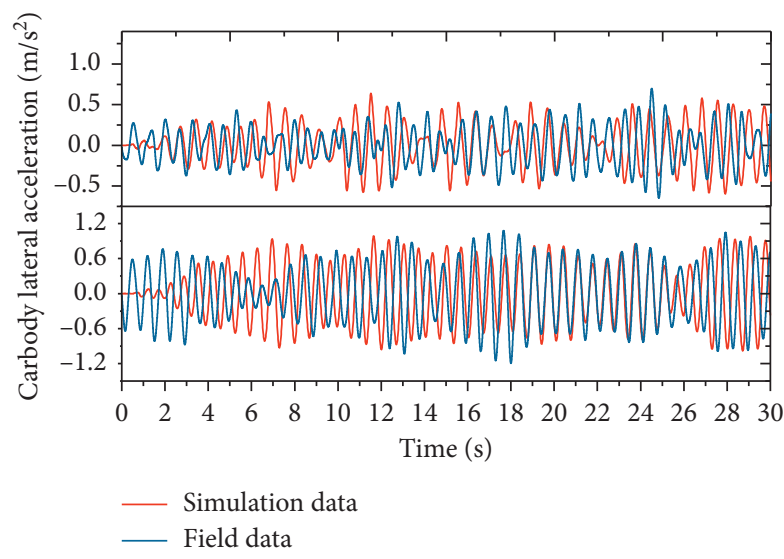

(a)

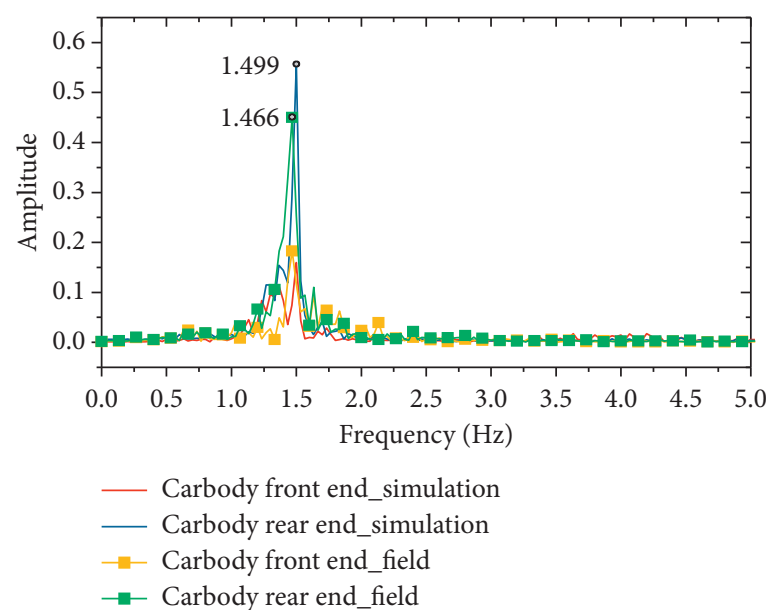

(b)

FIgURE 7: Comparison between simulation and field data. (a) Time domain (band pass filtered by $0.5-3 \mathrm{~Hz}$ ) and (b) frequency domain.

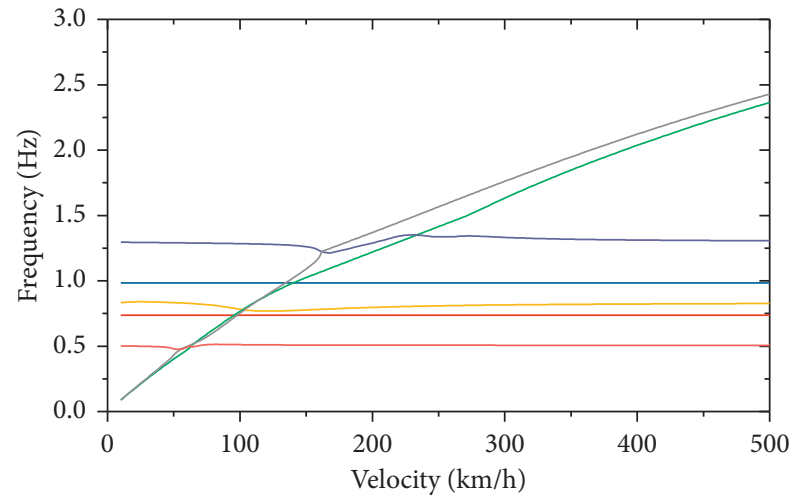

$\begin{array}{ll}\text { - Carbody bounce } & \text { Carbody pitch } \\ \text { C } & \text { Carbody lower swaying } \\ \text { Carbody yaw } & \text { 1\# hunting movement } \\ \text { Carbody upper } & \text { 2\# hunting movement } \\ \text { sawying }\end{array}$

(a)
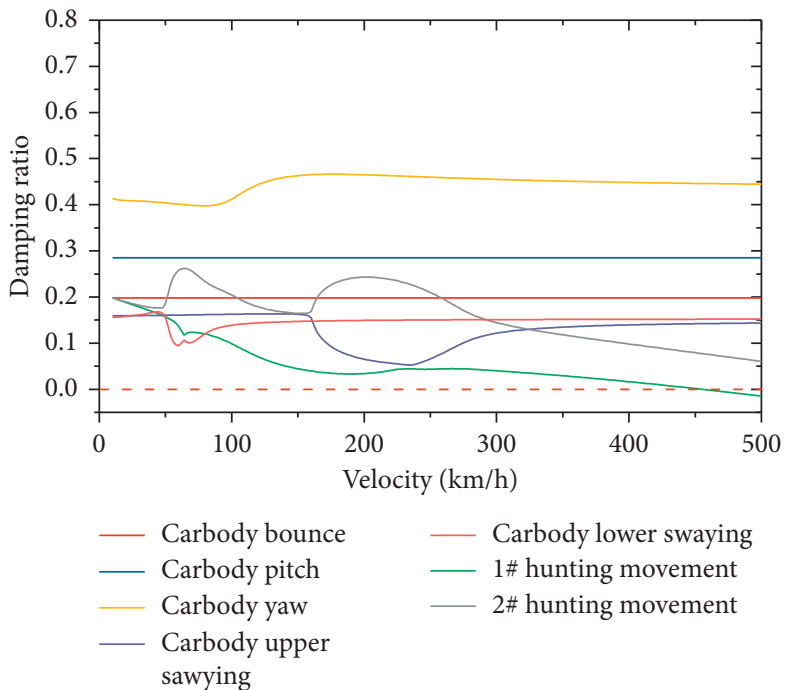

(b)

Figure 8: Analysis of eigenvalue on (a) frequency domain and (b) damping ratio.
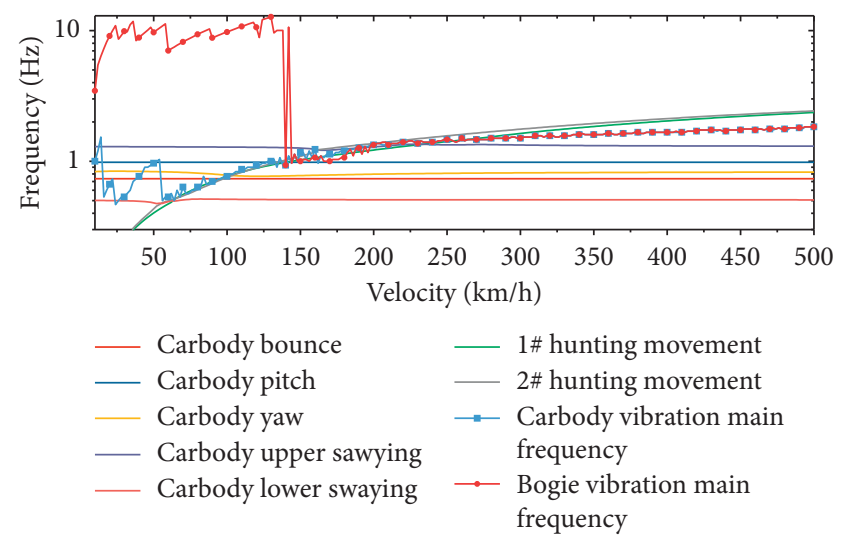

FIGURE 9: Vehicle vibration main frequency and carbody mode frequency. over $80 \%$. The increase in the ride index becomes steep, and the carbody begins to sway. In comparison to Figure 8(b), it can be seen that the damping ratio of the upper swaying mode and the first hunting movement significantly decreases. At this time, the carbody swaying is primarily caused by the carbody's hunting behavior. This is essentially the resonance between the upper swaying mode and the bogiehunting frequency. In addition, the ride index has increased significantly in Figure 10.

As the vehicle speed reaches $240 \mathrm{~km} / \mathrm{h}$, Figure 10 shows that the first hunting frequency also passes through the carbody upper swaying frequency mode. The ride index in Figure 10 has the first peak value, and thereafter, has a slight drop. When the vehicle speed exceeds $276 \mathrm{~km} / \mathrm{h}$, Figure 8(b) shows that the damping ratio of the upper swaying mode increased whilst the damping ratio of the hunting movement 


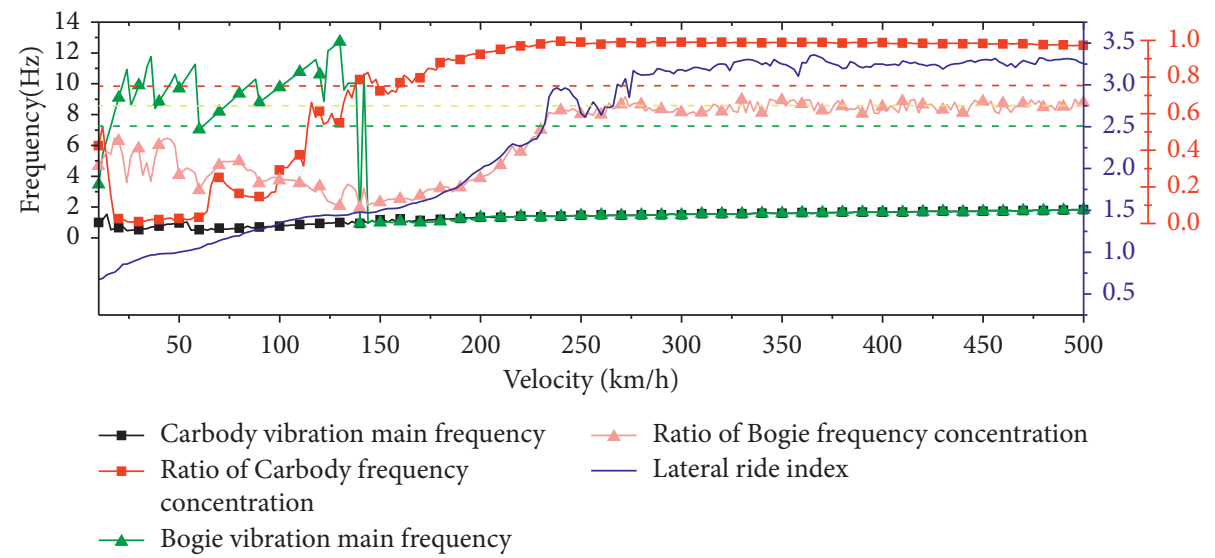

Figure 10: Carbody vibration characteristic and lateral ride index.

continues to decrease. At this point, the main frequency of the carbody vibration is distinctively different from one of the carbody's rigidity natural mode. The condition that caused a carbody hunting movement to disappear at this point is corresponding to the bogie-hunting mode with relatively low damping. With the increase in the vehicle speed, Figure 10 illustrates that the main frequency of the carbody and bogie frame also slowly increases. Figure 10 shows that the ride index exceeds 3.0 and stays below 3.5 without a major decreasing trend as the speed increased further. At this point, the energy concentration rate of vehicle body vibration has also remained high for speeds exceeding $250 \mathrm{~km} / \mathrm{h}$, i.e., over $97 \%$.

From Figures $8(\mathrm{~b})$ and Figure 10, it is evident that there is a carbody hunting movement at $240 \mathrm{~km} / \mathrm{h}$ with low conicity. When operating at $300 \mathrm{~km} / \mathrm{h}$ and higher speeds, the frequency of carbody vibration and the main frequency of each carbody natural mode are different. However, the damping ratio of each mode is not relatively low.

Figure 11 illustrates a verification of the carbody swaying mechanism under high-speed conditions, namely, the bifurcation diagram of a nonlinear system, the measured railLMB10 profile, and nonlinear critical speed, respectively. This was accomplished using the methods of speed reduction and changing the excitation amplitude. In the figure, the number in parentheses after the wheel profile represents the measured wheel profiles after running the corresponding kilometer.

The "w" in the brackets means the corresponding operation distance in unit of $10,000 \mathrm{~km}$, for instance, LMB10 (15w) means the LMB10 wheel's profile is measured after $150,000 \mathrm{~km}$ operation distance. Figure 11(a) shows the relationship between equivalent conicity, which is calculated by UIC519 [33] and lateral displacement for these considered wheel-rail contact situations. Figure 11(b) shows that the vehicle system's bifurcation under the measured railway system and LMB10 profile is a typical subcritical bifurcation. Figure 11(c) indicates that a change in the wheel-rail relationship leads to a big difference in the amount of wheelset lateral displacement and the amplitude of the time-frequency characteristics. To easily identify the wavelet transformation result of each working condition,
Figure 11(d) normalizes the amplitude by multiplying it with the corresponding normalization coefficient. The normalization coefficients for CHN60-LMB10, CHN60-LMB10 (15w), CHN60-LMB10 (25w), CHN60-LMB10 (38w), measured rail-LMB10, and measured rail-LMB10 (38w) were $3.00,2.50,1.0,4.00,0.17$, and 1.60 , respectively.

Figure 11(c) shows that when the measured rail is matched with the LMB10 wheel profile, the equivalent conicity of the vehicle is only 0.054 , with a nonlinear critical speed of $176 \mathrm{~km} / \mathrm{h}$. This speed is much smaller than the other wheel-rail matching conditions with the amplitude of wheelset lateral movement being too large to meet the requirements for normal vehicle operations. When the equivalent conicity is increased to 0.081 with the worn wheel profiles, the nonlinear critical speed is greatly improved, reaching about $393 \mathrm{~km} / \mathrm{h}$. When the $\mathrm{CHN} 60$ matches the LMB10 wheel profile, the equivalent conicity is 0.110 with a nonlinear critical speed of about $435 \mathrm{~km} / \mathrm{h}$. This meets the standard requirements for regular vehicle operating conditions. With the vehicle's operation and the wear of the wheel, the wheelset equivalent conicity gradually increases from 0.110 to 0.391 whilst the critical speed dropped from $435 \mathrm{~km} / \mathrm{h}$ to $284 \mathrm{~km} / \mathrm{h}$. However, continued operation under these conditions may cause bogie-hunting alarms with the need for wheel profile reprofiling.

Figure 11(d) illustrates that the bogie-hunting stability frequency of the measured rail on the line, while the LMB10 wheel profile is extremely low, is about $1-2 \mathrm{~Hz}$. Since the equivalent conicity is not large, the vibration frequency is low, and the vibration amplitude may not reach the acceleration limit for the bogie-hunting stability criterion specified in GB5599-2019. This phenomenon happens even if the hunting stability causes the wheelset or the vehicle system to sway significantly. As the wheels wear to the limit, the hunting stability frequency is increased to about $3.1 \mathrm{~Hz}$. Also, when the CHN60 matches the LMB10 wheel profile, the hunting stability frequency is about 4.2 Hz. With an increase in wear, the hunting stability frequency first decreases slightly and then increases, as theoretically predicted. In general, the meandering frequency increases with an increase of the equivalent conicity. 


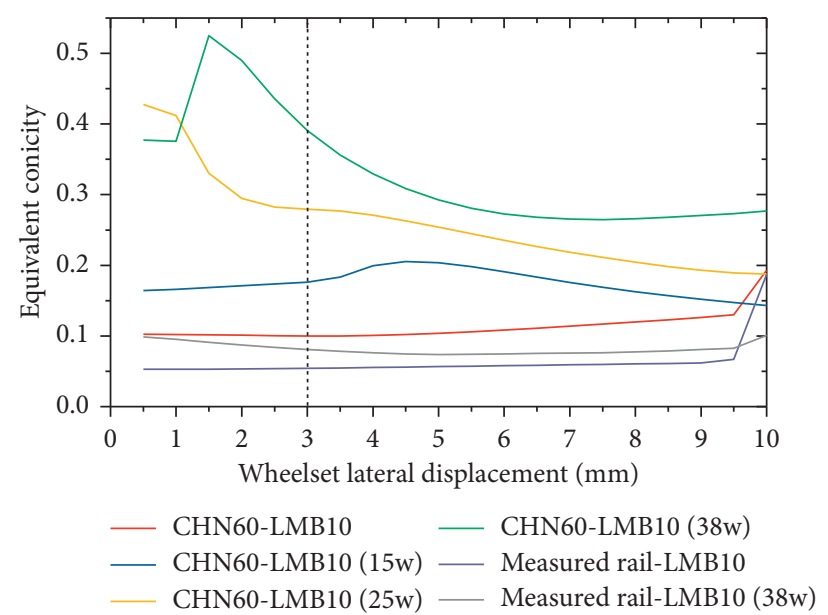

(a)

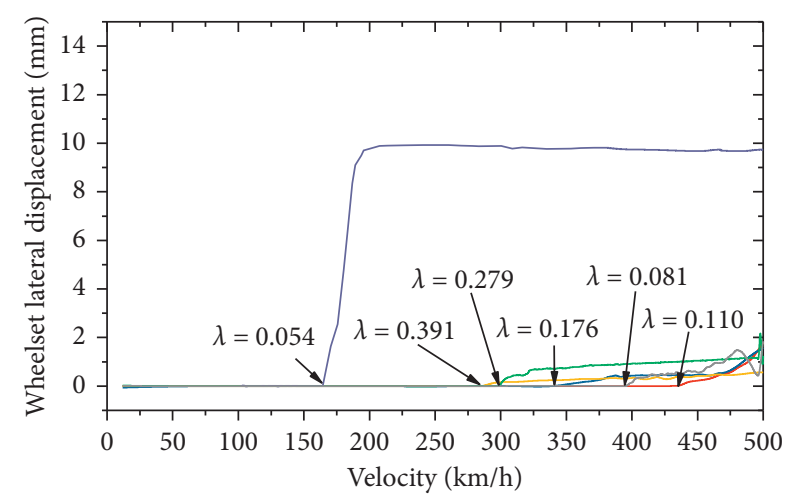

$\begin{array}{ll}\text { CHN60-LMB10 } & \text { CHN60-LMB10 (38w) } \\ \text { CHN60-LMB10 (15w) } & \text { Measured rail-LMB10 } \\ \text { CHN60-LMB10 (25w) } & - \text { Measured rail-LMB10 (38w) }\end{array}$

(c)

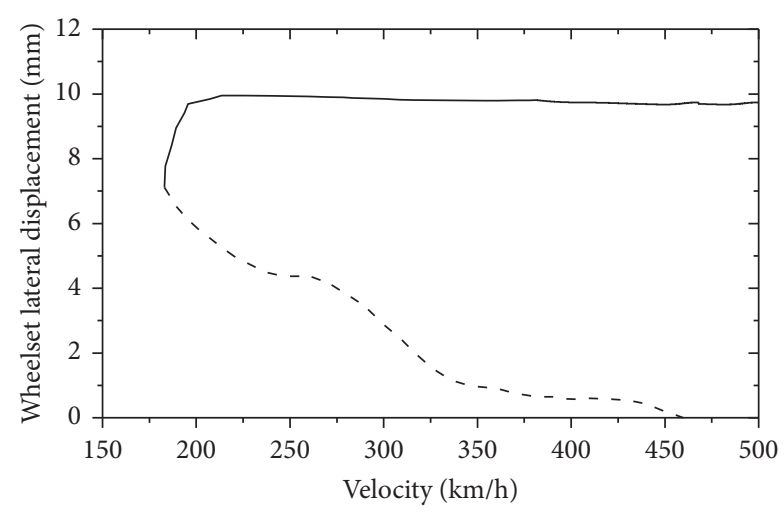

(b)

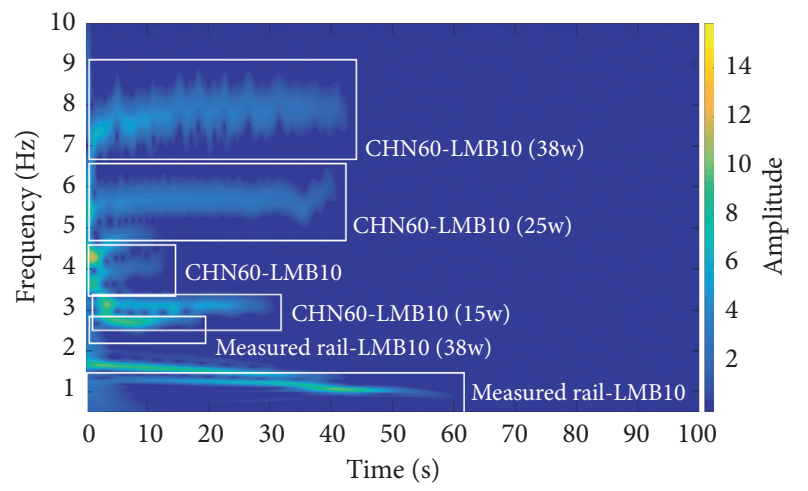

(d)

Figure 11: (a) The equivalent conicity between different rail profiles and wheel profiles. (b) The bifurcation diagram of vehicle under measured rail profile with LMB10 wheel profile. (c) Amplitude of limit cycles under different wheel-rail contact conditions. (d) Wheelset lateral displacement in time-frequency domain.

Based on the above analysis, Figure 10 shows that as the speed increases, the carbody sways first, and the ride index reaches the peak at $240 \mathrm{~km} / \mathrm{h}$. The hunting frequency is consistent with the carbody's upper swaying frequency with the damping ratio dropping significantly, exhibiting a more typical carbody hunting motion characteristic. As the speed increases, the ride index decreases slightly but then increases when the speed exceeds $275 \mathrm{~km} / \mathrm{h}$, while Figure 9 indicates the carbody's vibration main frequency has a certain difference with the various rigid modes of the carbody. This is different from the definition of carbody hunting motion. The bifurcation type of this vehicle with low contact conicity is a typical subcritical bifurcation, and the nonlinear critical speed is about $175 \mathrm{~km} / \mathrm{h}$, which is shown in Figures 11(b) and $11(\mathrm{c})$. When the vehicle speed exceeds the nonlinear critical speed, it will easily lead to the bogie-hunting phenomenon as the excitation amplitude exceeds the unstable bifurcation limit cycle amplitude. Based on these results, it is concluded that bogie-hunting motion is the primary cause of the low-frequency carbody swaying phenomenon at high vehicle speeds, which is transmitted to the carbody through the suspension system.

\section{Parametric Sensitivity Analysis}

This section of the paper focuses on the wheel-rail contact relationship, stiffness of the rotary arm attachment point, stiffness of the secondary airsprings, and the yaw damper's parameters to eliminate this swaying phenomenon. The wheel-rail contact optimization analysis mainly considers the contact relationship between the new/worn LMB10 wheel profiles and the actual measured/CHN60 rail profiles. The simulation, mainly based on changing the original parameters from 0.2 to 1.5 times of the rotary arm attachment point and the stiffness of the secondary airspring while from 0.2 to 3 times of the secondary lateral damping, analyzes the influence on the carbody swaying phenomenon. The initial value of the rotary arm attachment point stiffness was $72 \mathrm{MN} / \mathrm{m}$ with a secondary lateral stiffness of $0.135 \mathrm{MN} /$ $\mathrm{m}$ and a secondary lateral damping of $13 \mathrm{kN} \cdot \mathrm{s} / \mathrm{m}$, while the 


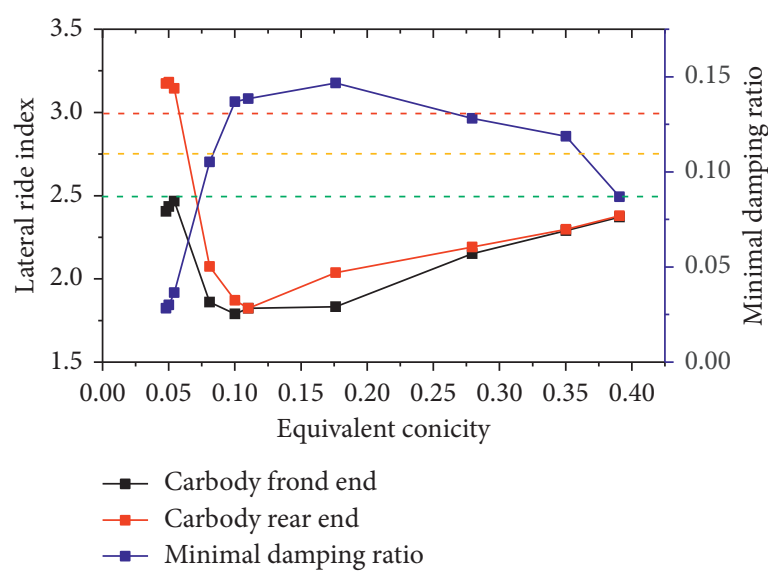

(a)

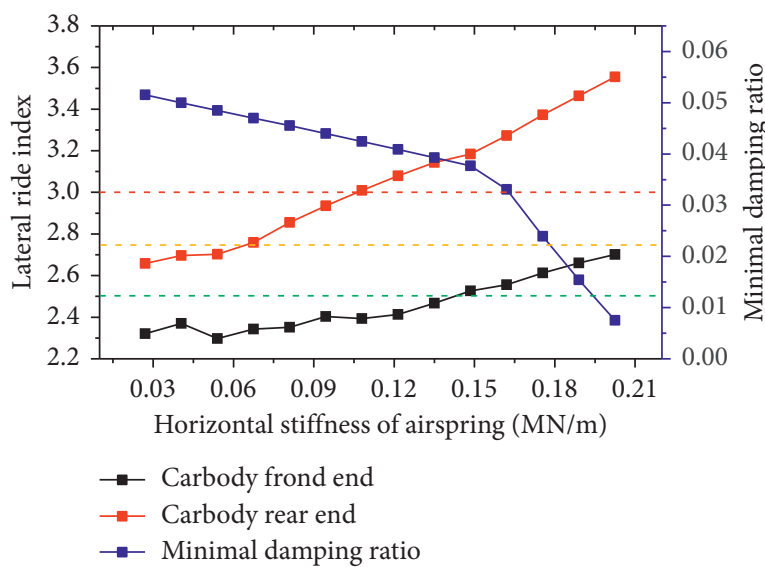

(c)

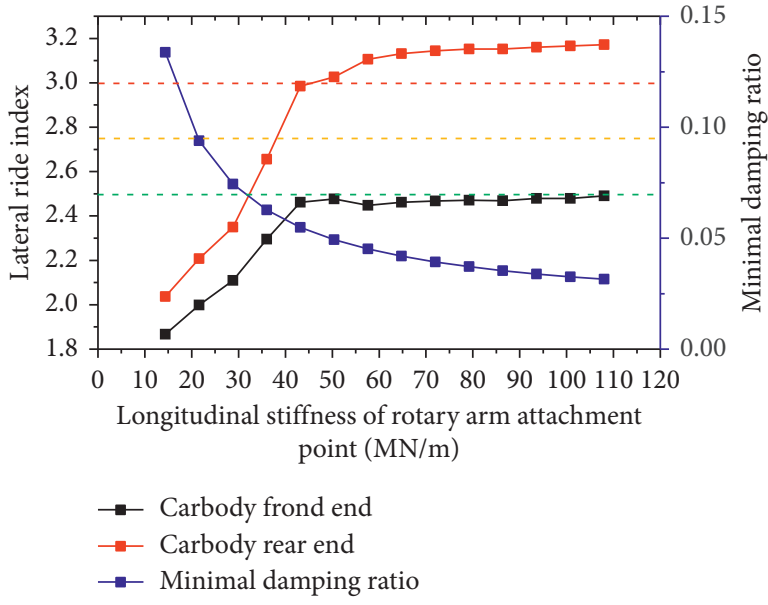

(b)

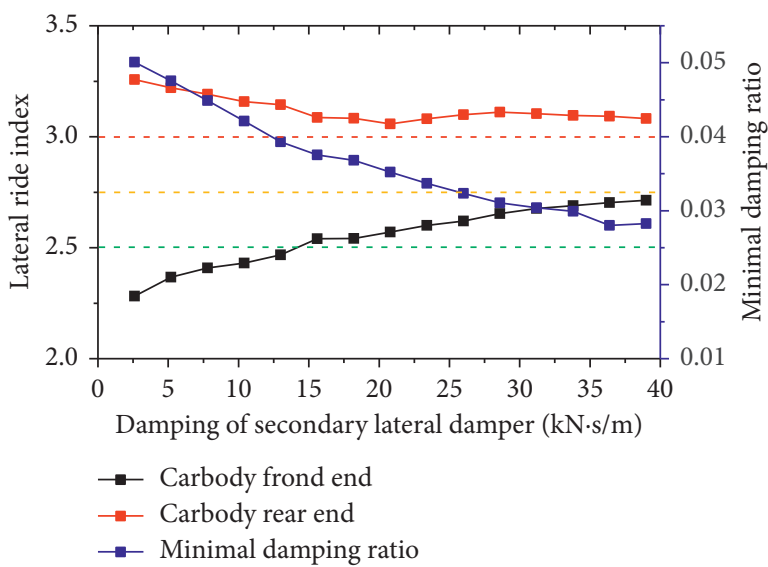

(d)

FIGURE 12: Optimized effect on lateral ride index and minimal damping ratio by (a) equivalent conicity, (b) longitudinal stiffness of rotary arm attachment point, (c) airspring, and (d) damping of secondary lateral damper.

running speed is $300 \mathrm{~km} / \mathrm{h}$. The optimization results are graphically shown in Figure 12.

Figure 12(a) indicates that with the extreme low equivalent conicity, the minimum damping ratio of the system is marginal and only about 0.025 , which is in a critical instability state. Meanwhile, the carbody rear-end ride index exceeds the limit of 3.0. There is the expected carbody swaying behavior. With a gradual increase in the equivalent conicity to 0.12 , the system's minimum damping ratio increased, resulting into a significant improvement in the carbody swaying phenomenon. However, the ride index drops below 2.00. When the equivalent conicity was continuously increased, the system's minimum damping ratio did not change much. Eventually as the wheel profile wears, the system's minimum damping ratio decreased significantly with the carbody's ride index continuing to deteriorate as well. It can be seen from Figure 12(b) that the smaller the longitudinal stiffness rotary arm attachment point, the greater the minimum damping ratio of the system and the better the carbody vibration. When the rotary arm attachment point longitudinal stiffness is 14.4 MN/m, the system's minimum damping ratio is the largest, which is 0.133 with a ride index of 2.00 . With an increase in the longitudinal stiffness, the system's minimum damping ratio reduced significantly with the carbody vibration intensifying significantly as well. When the rotary arm attachment point longitudinal stiffness reaches $50.4 \mathrm{MN} / \mathrm{m}$, the carbody rear-end ride index exceeds 3.00. As the longitudinal stiffness increases continuously, the minimum damping ratio of the system starts to decrease gradually. It is observed in Figure 12(c) that the lower the horizontal stiffness of the secondary airspring, the greater the minimum damping ratio of the system. However, compared to the optimization effect of the equivalent conicity and the rotary arm attachment point, the optimization effect of the airspring is relatively limited. Even if the horizontal stiffness of the airspring is reduced to $0.027 \mathrm{MN} /$ $\mathrm{m}$, the system's minimum damping ratio is only 0.05 with the ride index reaching 2.65. The Figure 12(d) shows that with the increase of the secondary lateral damper damping from $2.6 \mathrm{kN} \cdot \mathrm{s} / \mathrm{m}$ to $39 \mathrm{kN} \cdot \mathrm{s} / \mathrm{m}$, there is a slight downward trend of the minimum damping ratio. Meanwhile, the ride index of carbody front-end increases from 2.3 to 2.7, while the ride index of carbody rear end remains unchanged. It is 
generally considered that the optimization of secondary lateral damper on the carbody swaying behavior is not obvious.

Since the yaw damper's dynamic parameters significantly impact the vehicle stability, three yaw dampers' measured parameters were adopted, namely, 1\#, 2\#, and 3\# dampers, respectively. The stiffness and damping characteristics of these dampers are shown in Figures 12(a) and 12(b). The equivalent stiffness of these dampers were approximately $16.28 \mathrm{MN} / \mathrm{m}, 8.89 \mathrm{MN} / \mathrm{m}$, and $5.48 \mathrm{MN} / \mathrm{m}$, respectively, with an equivalent damping of approximately $428 \mathrm{kN} \cdot \mathrm{s} / \mathrm{m}, 428 \mathrm{kN} \cdot \mathrm{s} / \mathrm{m}$ (damping less than 1 \#'s after unloading), and $330 \mathrm{kN} \cdot \mathrm{s} / \mathrm{m}$, respectively. Nine matching conditions that combine the equivalent stiffness and damping of the three yaw dampers are shown in Figure 13(c) along with the optimization effect. Among these, $\mathrm{K}$ and $\mathrm{C}$ represent the stiffness and damping, and the number represents the number of the damper. $\mathrm{K} 1-\mathrm{C} 1$ is the original working condition.

Figure 13(c) illustrates that the yaw damper's damping has a significant effect on the carbody swaying phenomenon. Among the three yaw dampers investigated, the smaller the damping, the more effective it is to reduce the carbody swaying phenomenon. When the damping value is $428 \mathrm{kN} \cdot \mathrm{s} /$ $\mathrm{m}$, the carbody rear end's ride index is 3.14 . However, when the damping is reduced to $330 \mathrm{kN} \cdot \mathrm{s} / \mathrm{m}$, the index drops to 2.24 , which is optimized by $28 \%$ with the out-of-limit ride index upgrading to excellent state. When compared with the damping value change, the yaw damper's stiffness has no apparent sensitivity in improving the swaying.

From the above analysis, adjusting the appropriate wheel-rail contact relationship, reducing the longitudinal stiffness of the rotary arm attachment point, and the damping of the yaw damper can effectively reduce the carbody's swaying behavior. The optimization result is shown in Figure 14.

Figure 14(a) points out that the three effective methods can effectively reduce the amplitude of the carbody swaying, control the vehicle-swaying phenomenon, and greatly improve the stability index. According to Figure 14(b), by changing the wheel-rail contact relationship, the original $1.5 \mathrm{~Hz}$ peak of the swaying frequency completely disappears with a shallow amplitude peak appearing at the higher frequency (i.e., at about $2.75 \mathrm{~Hz}$ ). Overall, there was no distinct peak for the vibration main frequency. There is still a small peak near the original frequency even though the methods of reducing the rotary arm attachment points longitudinal stiffness and the yaw damper's equivalent damping can also reduce the vibration peak of the carbody. This shows that the two methods can reduce the coupling relationship among the wheelset, the bogie frame, and the carbody while the hunting motion transmission can be reduced by changing the suspension parameters. Similarly, the energy to the carbody can be essentially eliminated by changing the wheel-rail contact relationship.

It is worth noting that reducing the suspension elemental parameters can cause abnormal vibrations and even instability of the vehicle, particularly those with worn wheel profiles. In Figure 15, an analysis between the changed suspension parameters is shown with worn wheel profiles. In the analysis, the lateral ride index was computed as the average value of the carbody's front and rear measurement points. The bogie frame's acceleration was filtered within the $0.5-40 \mathrm{~Hz}$ frequency with a four-order Butterworth filter. The effective conicity between the measured rail and the worn wheel profile is 0.081 with an equivalent conicity of 0.391 between the standard rail and the worn wheel profile.

Figure 15(a) indicates that the bogie frame vibration is relatively similar to the original longitudinal stiffness parameters and the optimized parameters, for both the CHN60 railway profile matched with LMB10 standard wheel profile, and the measured rail profile matched with the worn wheel profile. However, the carbody ride index with the optimized parameters is superior when the original parameters are used under the matching of CHN60 rail profile and LMB10 standard wheel profile or measured rail profile and LMB10 worn wheel profile. When the CHN60 rail profile matches the worn wheel, the root mean square (RMS) value and maximum (MAX) value of the bogie frame lateral acceleration (with the adjusted parameters significantly greater than the ones with the original parameters) increased from $1.691 \mathrm{~m} / \mathrm{s}^{2}$ and $7.021 \mathrm{~m} / \mathrm{s}^{2}$ to 2.291 and $8.403 \mathrm{~m} / \mathrm{s}^{2}$ at incremental rate of $35.5 \%$ and $15.4 \%$, respectively. The ride index did not change significantly in the current conditions. Figure 15(b) indicates that the bogie frame vibration under the adjustment of the yaw damper also exhibits a similar situation. When the CHN60 rail matches the LMB10 wheel profile or the measured rail matches the worn wheel, the difference is not significant either. The vibration with optimized parameters increased significantly with the matching of the CHN60 rail and the worn wheel with the average and maximum values increasing by $45.8 \%$ and $30.2 \%$, respectively. Simultaneously, the vehicle ride index significantly deteriorated due to an increase in the bogie frame vibration.

Based on the above analysis, it can be seen that changing the suspension elemental parameters can indeed improve the carbody swaying phenomenon. However, when subjected to long-term operations, the wheel profile wear will obviously increase, and, so, will be the vibration of the bogie frame-ultimately leading to hunting motion and even stability. Fundamentally, solving the carbody swaying behavior requires changing the wheel-rail contact relationship, which is resolvable by reshaping the rail profile or adjusting the operation traffic route. This ultimately allows vehicles with worn wheel profile to operate on the rail line.

Figure 16 shows that the vehicle returns to this line with the worn wheel profile after running on other lines with an equivalent conicity of 0.101 .

Figure 4 shows that with the matching of new wheel profile and the physically measured rail profile, the ride index is bad. The proportion of the test data corresponding to well, qualified, and unqualified (i.e., out of limit) levels were $9.43 \%, 13.30 \%$, and $18.34 \%$, respectively. Contrary to this, the data in Figure 16(a), with an optimized contact relationship, show a reduction to $0 \%, 0.29 \%$, and $2.88 \%$, respectively. This illustrates that the ride index of the carbody has been improved significantly due to improvement in 


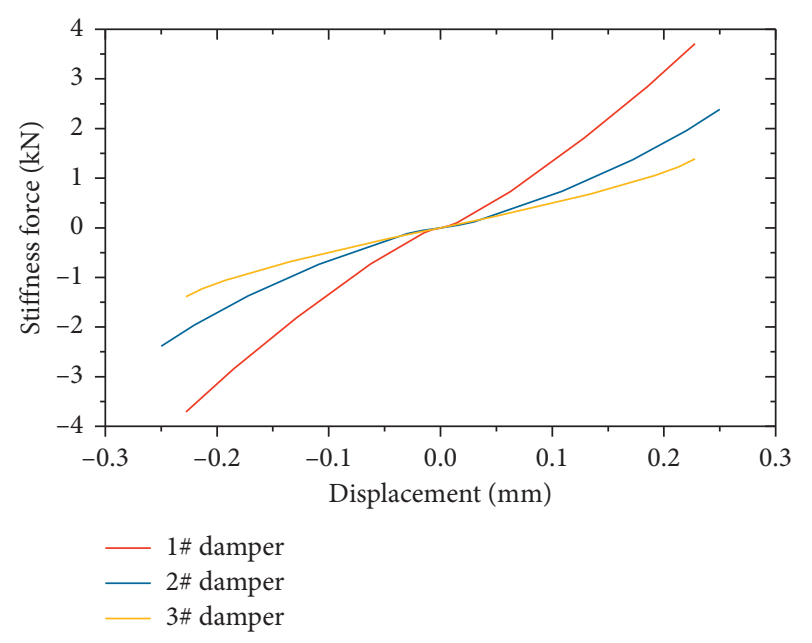

(a)

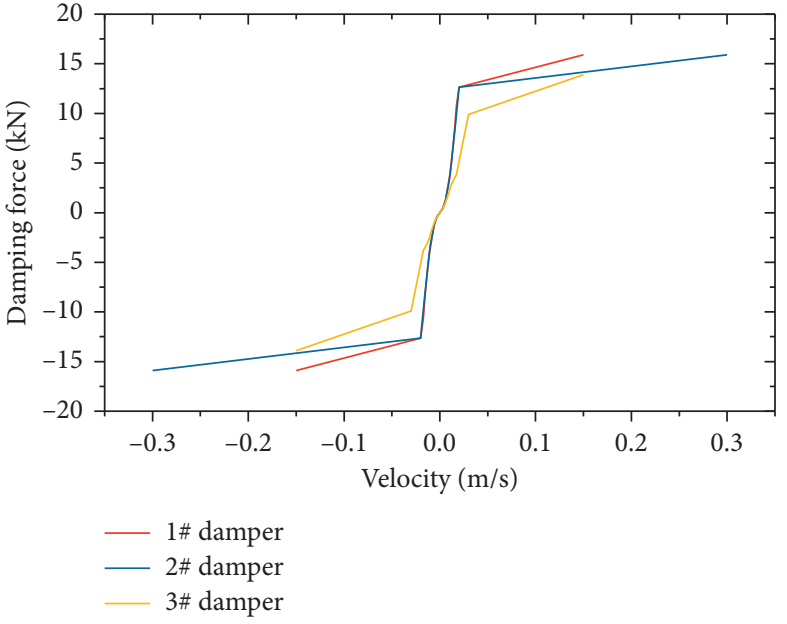

(b)

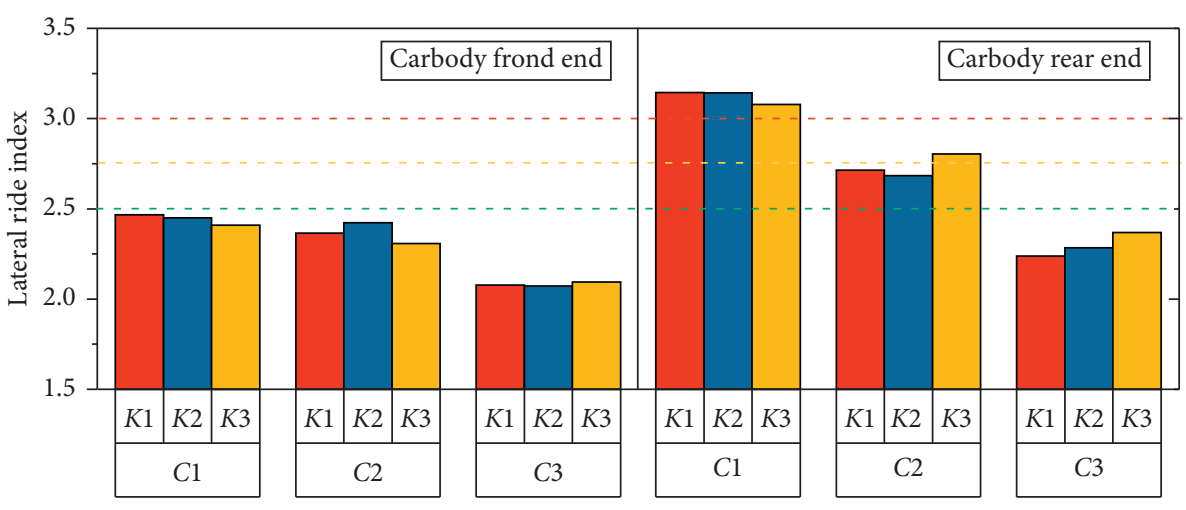

(c)

Figure 13: Parameter characteristic of yaw damper. (a) Damping characteristic, (b) stiffness characteristic, and (c) the optimized effect on lateral ride index by yaw damper.

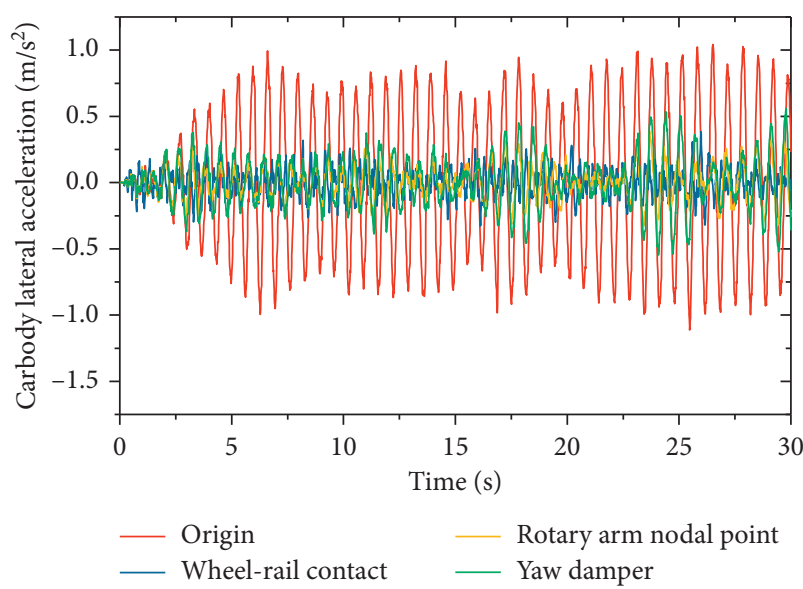

(a)

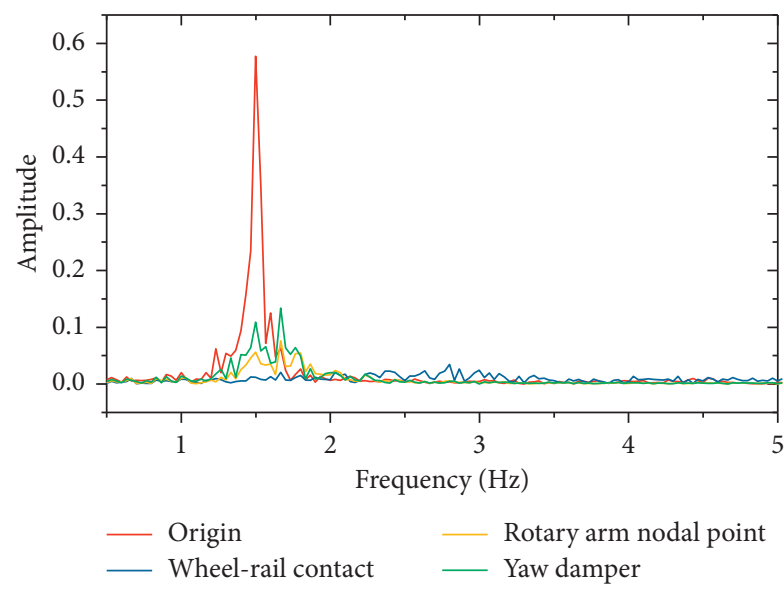

(b)

FIGURE 14: Improved result of different optimized methods on (a) time domain and (b) frequency domain.

the wheel-rail contact relationship. The front and rear vibration acceleration of the carbody, as filtered within the $0.5-3 \mathrm{~Hz}$ frequency, was also reduced significantly in
Figure 16(b). The line test verified that the abnormal wheelrail contact relationship was indeed the direct cause of the carbody swaying. Overall, the results showed that by 


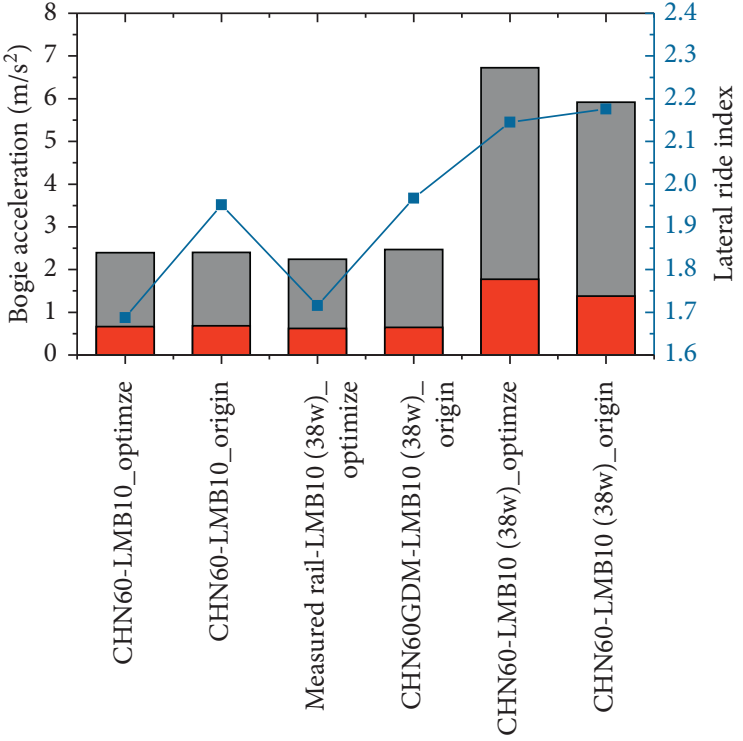

MAX RMS

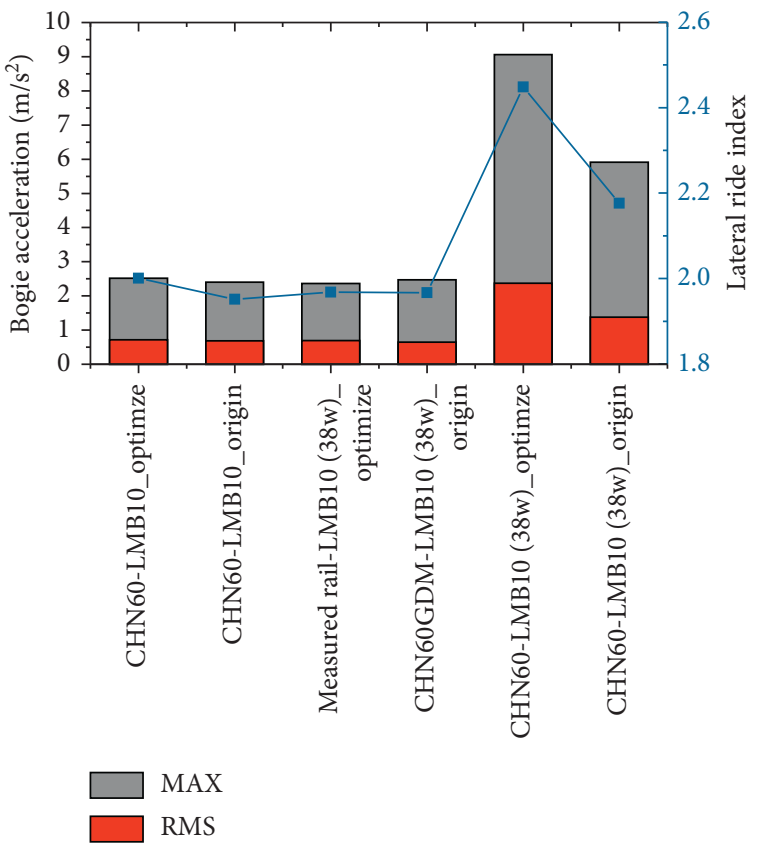

(b)

FIGURE 15: Vibration comparison between the optimized and original parameters. (a) Longitudinal stiffness of rotary arm attachment point and (b) yaw damper (MAX = maximum and $\mathrm{RMS}=$ root mean square).

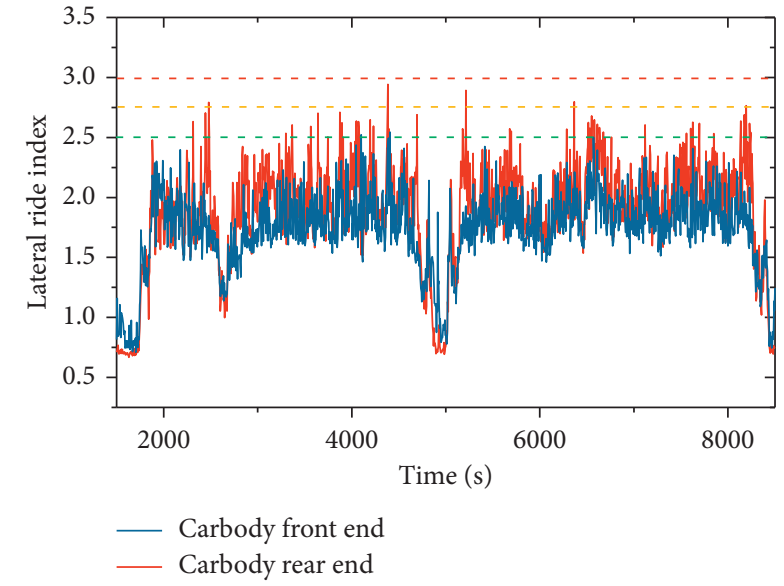

(a)

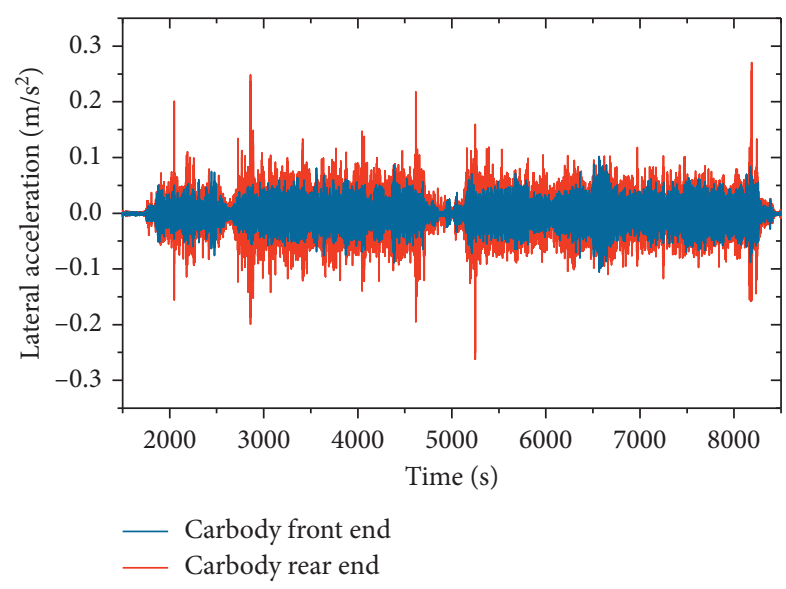

(b)

FIGURE 16: Carbody vibration with optimized wheel-rail contact. (a) Lateral ride index and (b) lateral acceleration.

improving the wheel-rail contact relationship, low-frequency carbody swaying under low contact conicity could be mitigated.

\section{Conclusions}

Based on the field test and simulation analysis of the carbody swaying phenomenon under low contact conicity presented in this paper, the following conclusions can be drawn:

(1) The field test showed that, unlike traditional cognition, the carbody swaying phenomenon can also occur at high speeds. This can significantly affect the ride index and the passenger's comfort with the carbody swaying behavior.

(2) Unlike the traditional carbody hunting stability, carbody swaying at high speed is also a function of the bogie-hunting motion caused by the low equivalent conicity and the unreasonable matching of the suspension parameters under the wheel-rail matching relationship. For carbody swaying motion (where the direct cause is thought to be abnormal rail profile), the analysis shows that the swaying is not 
necessarily caused by the carbody hunting motion alone. The bogie-hunting motion can also cause the carbody swaying motion under certain circumstances and boundary conditions.

(3) By improving the wheel-rail contact relationship, reducing the longitudinal stiffness of the rotary arm attachment point and reducing the damping and stiffness of the yaw damper, the carbody swaying phenomenon can be effectively reduced or eliminated. However, when the vehicle runs on a standard line with worn wheel profile, the adjusted suspension system parameters may cause increased vibrations or even vehicle's instability, thus posing a potential threat/risk to operational safety.

(4) Reprofiling the rail line can significantly contribute to solving the carbody swaying problem. In terms of economy and costs, the operation plan could be adjusted to make the vehicle run on the other lines and return to the measured line with the worn wheel profile. The measured data showed that this method can effectively mitigate the low-frequency carbody swaying phenomenon under low contact conicity.

\section{Data Availability}

The data used to support the findings of this study are available from the corresponding author upon request.

\section{Conflicts of Interest}

The authors declare that there are no conflicts of interest with respect to the research, authorship, and/or publication of this article.

\section{Acknowledgments}

This project was supported by the National Natural Science Foundation of China (Grant no. U2034210), the Program of State Key Laboratory of Traction Power (Grant nos.2018TPL_T11 and 2019TPL_T18), and Sichuan Science and Technology Project (Grant No. 2020YJ0074).

\section{References}

[1] R. Luo and H. Shi, High-speed Train System Dynamics, Southwest Jiaotong University Press, Chengdu, China, 2019.

[2] Z. H. Xia, J. Zhou, J. Liang et al., "Online detection and control of car body low-frequency swaying in railway vehicles," $V e$ hicle System Dynamics, vol. 59, no. 1, pp. 70-100, 2019.

[3] J. Sun, M. Chi, X. Jin, S. Liang, J. Wang, and W. Li, "Experimental and numerical study on carbody hunting of electric locomotive induced by low wheel-rail contact conicity," Vehicle System Dynamics, vol. 0, pp. 1-21, 2019.

[4] A. Matsumoto, Y. Sato, H. Ohno et al., "Compatibility of curving performance and hunting stability of railway bogie," Vehicle System Dynamics, vol. 33, no. sup1, pp. 740-748, 1999.

[5] S. Bruni, F. Cheli, A. Collina, and F. Resta, "Road test data procedures for evaluating the hunting instability threshold of a railway vehicle from on board measurements," Vehicle System Dynamics, vol. 33, no. sup1, pp. 168-179, 1999.
[6] Y.-C. Cheng, S.-Y. Lee, and H.-H. Chen, "Modeling and nonlinear hunting stability analysis of high-speed railway vehicle moving on curved tracks," Journal of Sound and Vibration, vol. 324, no. 1-2, pp. 139-160, 2009.

[7] P. Kim and J. Seok, "Bifurcation analysis on the hunting behavior of a dual-bogie railway vehicle using the method of multiple scales," Journal of Sound and Vibration, vol. 329, no. 19, pp. 4017-4039, 2010.

[8] W. M. Zhai and K. Y. Wang, "Lateral hunting stability of railway vehicles running on elastic track structures," Journal of Computational and Nonlinear Dynamics, vol. 5, pp. 1-9, 2010.

[9] O. Polach and I. Kaiser, "Comparison of methods analyzing bifurcation and hunting of complex rail vehicle models," Journal of Computational and Nonlinear Dynamics, vol. 7, pp. 1-8, 2012.

[10] L. Mazzola, S. Alfi, and S. Bruni, "Evaluation of the hunting behaviour of a railway vehicle in a curve," Proceedings of the Institution of Mechanical Engineers, Part F: Journal of Rail and Rapid Transit, vol. 229, no. 5, pp. 530-541, 2014.

[11] X. H. Zeng, H. Wu, J. Lai et al., "Hunting stability of highspeed railway vehicles on a curved track considering the effects of steady aerodynamic loads," Journal of Vibration and Control, vol. 22, pp. 4159-4175, 2015.

[12] Z. Li, M. Molodova, A. Nunez, and R. Dollevoet, "Improvements in axle box acceleration measurements for the detection of light squats in railway infrastructure," IEEE Transactions on Industrial Electronics, vol. 62, no. 7, pp. 4385-4397, 2015.

[13] Y. Yan and J. Zeng, "Hopf bifurcation analysis of railway bogie," Nonlinear Dynamics, vol. 92, no. 1, pp. 107-117, 2018.

[14] V. Kumar, V. Rastogi, and P. Pathak, "Modelling and evaluation of the hunting behaviour of a high-speed railway vehicle on curved track," Proceedings of the Institution of Mechanical Engineers, Part F: Journal of Rail and Rapid Transit, vol. 233, no. 2, pp. 220-236, 2018.

[15] Y. Ujita, "Recent research and development into vehicle technology," Quarterly Report of RTRI, vol. 60, no. 4, pp. 229-232, 2019.

[16] T. Matsudiara, "Hunting problem of high-speed railway vehicles with special reference to bogie design for the new tokaido line," Institution of Mechanical Engineers Proceedings, vol. 180 , pp. $58-72,1965$.

[17] H. Fujimoto and M. Miyamoto, "Measures to reduce the lateral vibration of the tail car in a high speed train," Proceedings of the Institution of Mechanical Engineers, Part F: Journal of Rail and Rapid Transit, vol. 210, no. 2, pp. 87-93, 1996.

[18] H. Fujimoto, K. Tanifuji, and M. Miyamoto, "Influence of track gauge variation on rail vehicle dynamics (an examination based on comparison between data from a test train running on track with irregularity artificially set and numerical simulation)," Proceedings of the Institution of Mechanical Engineers, Part F: Journal of Rail and Rapid Transit, vol. 214, no. 4, pp. 223-230, 2005.

[19] S. C. Sun, W. D. Wang, J. C. Liu et al., "Study of carbody's severe vibration based on stability analysis of vehicle system," China Railway Science, vol. 33, pp. 82-88, 2012.

[20] C. Huang, J. Zeng, and S. Liang, "Carbody hunting investigation of a high speed passenger car," Journal of Mechanical Science and Technology, vol. 27, no. 8, pp. 2283-2292, 2013.

[21] H. Shi and P. Wu, "Flexible vibration analysis for car body of high-speed EMU," Journal of Mechanical Science and Technology, vol. 30, no. 1, pp. 55-66, 2016. 
[22] L. Wei, J. Zeng, M. Chi, and J. Wang, "Carbody elastic vibrations of high-speed vehicles caused by bogie hunting instability," Vehicle System Dynamics, vol. 55, no. 9, pp. 1321-1342, 2017.

[23] H. Shi, J. Wang, P. Wu, C. Song, and W. Teng, "Field measurements of the evolution of wheel wear and vehicle dynamics for high-speed trains," Vehicle System Dynamics, vol. 56, no. 8, pp. 1187-1206, 2018.

[24] R. Luo, H. Shi, J. Guo, L. Huang, and J. Wang, "A nonlinear rubber spring model for the dynamics simulation of a highspeed train," Vehicle System Dynamics, vol. 58, no. 9, pp. 1367-1384, 2020.

[25] C. Lei, S. C. Wang, B. L. Guo et al., "Study on low-frequency lateral swaying of 2B0 locomotive," Journal of the China Railway Society, vol. 41, pp. 42-49, 2019.

[26] M. R. Chi, W. B. Cai, S. L. Liang et al., "Influences of rail grinding deviations on vehicle dynamics performances of high speed railways," China Mechanical Engineering, vol. 30, pp. 261-265, 2019.

[27] J. Zeng, L. Wei, M. R. Chi et al., "Hunting stability and improvement measures for high speed vehicles," in Proceedings of the Stephenson Conference Research for Railways 2015, pp. 441-452, Institution of Mechanical Engineers, London, UK, April 2015.

[28] G. Li, J. Zeng, M. R. Chi et al., "Study on the improvement of wheel-rail matching relationship for high speed train," Journal of Mechanical Engineering, vol. 54, no. 4, pp. 93-100, 2018.

[29] M. R. Hou, D. Cheng, and X. Y. Hu, “Optimal Design Of Wheelset Guidance Stiffness For High-Speed Passenger Car," in Proceedings of the 11th International Conference on Contact Mechanics and Wear of Rail/wheel Systems, CM 2018, pp. 397-402, TU Delft, Delft, Netherlands.

[30] Y. Wu, J. Zeng, Q. S. Wang et al., "Evaluation methods of carbody hunting instability of railway vehicles," in Proceedings of the 26th Symposium of the International Association of Vehicle System Dynamics, IA VSD 2019, pp. 908-914, Springer Nature, Gothenburg, Sweden, August 2019.

[31] J. F. Sun, M. R. Chi, W. B. Cai et al., "An investigation into evaluation methods for ride comfort of railway vehicles in the case of carbody hunting instability," Proceedings of the Institution of Mechanical Engineers, Part F: Journal of Rail and Rapid Transit., 2020.

[32] D. L. Chen and G. Shen, "Analysis of railway vehicle carbody hunting based on similarity identification of fuzzy mathematics," in Proceedings of the 25th Symposium of the International Association of Vehicle System Dynamics, IAVSD 2017, pp. 1019-1024, CRC Press/Balkema, Rockhampton, QLD, Australia, August 2017.

[33] UIC519-2004, Method for Determining the Equivalent Conicity, Union Internationale des Chemins de Fer, Paris, France, 2004.

[34] GB/T5599-2019, Specification for Daynamic Performance Assessment and Testing Verification or Rolling Stock, Standardization Administration of China, Beijing, China, 2019. 